\title{
Hydrogen ion dynamics as the fundamental link between Neu- rodegenerative Diseases and Cancer. Its application to the ther- apeutics of Neurodegenerative Diseases with special emphasis in Multiple Sclerosis.
}

\author{
Salvador Harguindey ${ }^{1, *}$, Khalid Alfarouk ${ }^{2}$, Julián Polo Orozco ${ }^{1,}$, Stephan J. Reshkin ${ }^{3}$ and Jesús Devesa ${ }^{4}$. \\ ${ }^{1}$ Division of Oncology, Institute of Clinical Biology and Metabolism, 01004 Vitoria, Spain; salvaszh@tele- \\ fonica.net \\ ${ }^{2}$ Alfarouk Biomedical Research LLC, Tampa, FL 33617, USA; Alfarouk@hala-alfarouk.org \\ ${ }^{1}$ Division of Oncology, Institute of Clinical Biology and Metabolism, 01004 Vitoria, Spain; \\ polorozco@gmail.com \\ ${ }^{3}$ Department of Biosciences, Biotechnology and Biopharmaceutics, University of Bari, Via E. Orabona 4, \\ 70125 Bari, Italy; stephanjoel.reshkin@uniba.it \\ ${ }^{4}$ Scientific Direction, Foltra Medical Centre, 15886 Teo, Spain; jesus.devesa@usc.es \\ * Correspondence: salvaszh@telefonica.net; Tel.: +34-629-047-141.
}

\begin{abstract}
The pH-related metabolic paradigm has rapidly grown in cancer research and treatment. In this contribution, this recent oncological perspective has been laterally for the first time in order to integrate neurodegeneration within the energetics of the cancer acid-base conceptual frame. At all levels of study, molecular, biochemical, metabolic and clinical, the intimate nature of both processes appears to be opposite mechanisms occurring at the far ends of a physiopathological intracellular $\mathrm{pH} / \mathrm{extracellular} \mathrm{pH}(\mathrm{pHi} / \mathrm{pHe})$ spectrum. This wide-ranged original approach now permits an increase in our understanding of these opposite processes, cancer and neurodegeneration, and, as a consequence, allows to propose new avenues of treatment based upon the intracellular and microenvironmental hydrogen ion dynamics regulating and deregulating the biochemistry and metabolism of both cancer and neural cells. Under the same perspective, the etiopathogenesis and special characteristics of multiple sclerosis (MS) becomes an excellent model for the study of neurodegenerative diseases and, utilizing this pioneering approach, we find that MS appears to be a metabolic disease even before an autoimmune one. Also within this paradigm, several important aspects of MS, from mitochondrial failure to microbiota functional abnormalities, are analyzed in depth.
\end{abstract}

Keywords: neurodegenerative diseases - multiple sclerosis; new therapeutic options for multiple sclerosis and other neurodegenerative diseases. $\mathrm{pH}$ in cancer and neurodegenerative diseases - cancer and neurodegeneration as opposed processes - metabolic etiopathogenesis of cancer and human neurodegenerative diseases

\section{Introduction}

As a classical approach to disease in general [1], the concept of homeostasis was initially defined by a balanced and healthy physiological situation of cells, tissues and systems of the organism. During the first part of the XX Century, Walter Cannon and Hans Selye initiated the seminal studies on the concept of homeostasis. However, the concept of acid-base balance was initially disregarded from belonging to the homeostatic approach [2]. These precedents inspired Hans Selye to create his famous General Adaptation Syndrome, a dynamic mixture of homeostasis and allostasis [3]. Later on, these concepts spread out to include acid-base equilibrium and disequilibrium within its 
physiopathological range. A healthy state of local and systemic homeostasis is fundamental for the correct functioning of all cells, organs and tissues of the organism. This requires that its normal parameters are kept within very narrow limits. The new $\mathrm{pH}$-centric anticancer paradigm [4,5] can now be applied, as an extension of one of these fields, oncology, into the other, neurodegeneration. This translational and transversal research among farapart separates fields, will allow to better understanding the intimate nature of the $\mathrm{pH}$ related deregulation of this homeostatic $\mathrm{pH}$-related approach that shows that cancer and neurodegeneration are two opposed situations from an acid-base and energetic homeostatic spectrum. This becomes evident, no matter at which level of analysis, either molecular, metabolic, biochemical, or even clinical [6-9], this is approached (Table 1). Indeed, this perspective permits a deeper understanding of the intimate nature of both disease processes.

Table 1. pHi and pHe in normal cells, HNDDs neurons and cancer cells: apoptosis and antiapoptosis [4,6,10]. pHi: intracellular $\mathrm{pH}$; $\mathrm{pHe}$ : extracellular $\mathrm{pH}$; HNNDs: Human neurodegenerative diseases; CPR: Cancer proton reversal; TFWS: Trophic factor withdrawal syndrome. For further details, see text.

\section{NORMAL CELLS}

( $\mathrm{pHi}<\mathrm{pHe})$

pHi: 6.99-7.05

(CPR)

pHe: 7.35-7.45
HNDDs NEURONS

(Low pHi, Low pHe)

pHi: 6.2-6.8 (acid)

( $\downarrow$ pHi pathological apoptosis)

\author{
pHe: 6.0-6.8 (acid) \\ $(\downarrow$ pHi pathological apoptosis)
}

(TFWS)

\section{CANCER CELLS \\ (pHi > pHe)}

\author{
pHi: 7.2-7.8 (alkaline) \\ ( $\uparrow$ pHi pathological antiapoptosis)
}

pHe: 6.0-6.8 (acid)

( $\uparrow$ Metastatic process)

\begin{abstract}
Acid pHi /Acid pHe
Alkaline pHi /Acid pHe

On etiopathogenesis. The intracellular-extracellular hydrogen ion $\left(\mathrm{H}^{+}\right)$and/or $\mathrm{pH} d y-$ namics and its abnormalities as the fundamental link between cancer and human neurodegenerative diseases (HNDDs) (Box 1).
\end{abstract}

Box 1. pH-related mechanisms in the etiopathogenesis of Multiple Sclerosis (MS), human neurodegenerative diseases (HNDDs) and cancer. MS: Multiple sclerosis; HNDDs: Human neurodegenerative diseases; PD: Parkinson's disease; ASIC1: Acid-sensing Ion channel type 1a; Hv1: Voltage-gated proton channel type 1.5; Nav1.5: Voltage-gated sodium channel isoform 1.5; GFs: Growth factors; PRGF: Plasma rich in growth factors. 


\begin{tabular}{|c|c|c|}
\hline Mechanism & Etiopathogenesis & References \\
\hline $\begin{array}{l}\text { Microenvironmental } \\
\text { acid } \mathrm{pH}\end{array}$ & $\begin{array}{l}\text { Like in all malignant tumors, a microenvironmental acidic } \\
\mathrm{pH} \text { is a fundamental hallmark of the demyelinating lesions } \\
\text { of MS and other HNDDs. This pathologicallly acidified pHe } \\
\text { decreases the migration, proliferation and survival of } \\
\text { oligodendrocyte precursor cells, also hindering the } \\
\text { differentiation into mature oligodendrocytes, while } \\
\text { inducing demyelinization while decreasing remylenization. } \\
\text { In AD, accumulation of } \beta \text {-amyloid }(\beta \mathrm{A}) \text { is directly induced } \\
\text { by acidosis. In PD, low neural cell pH induce protein } \\
\text { aggregation, mitochondrial dysfunction, oxidative stress } \\
\text { and neuroinflammation, all hallmarks from the disease. } \\
\text { Low pHi also activates pHi-dependent caspases and } \\
\text { endonucleases. }\end{array}$ & {$[8,10-31]$} \\
\hline $\begin{array}{c}\mathrm{H}^{+} \text {extrusion and } \\
\text { elevated } \mathrm{pHi}\end{array}$ & $\begin{array}{l}\mathrm{H}^{+} \text {extrusion on its own is a fundamental carcinogenic fac- } \\
\text { tor that induces cell transformation, growth and invasion } \\
\text { in BC and other tumors. On the contrary, } \mathrm{H}^{+} \text {extrusion is } \\
\text { an antiapoptotic measure in MS and HNDDs. }\end{array}$ & {$[6-8,32-44]$} \\
\hline $\begin{array}{l}\text { Ion channels (IOs) in } \\
\text { HNNDs pathogenesis }\end{array}$ & $\begin{array}{l}\text { IOs, mainly the isoform } \mathrm{ASIC1} \text {, favor an i. c. excessive ac- } \\
\text { cumulation of } \mathrm{Na}^{+}, \mathrm{Ca}^{++} \text {and } \mathrm{H}^{+} \text {in } \mathrm{MS} \text { and other HNDDs, } \\
\text { resulting in severe axonal degeneration and neural dam- } \\
\text { age secondary to } \mathrm{Ca}^{++} \text {overload and acidification-mediated } \\
\text { apoptosis. Tissue acidosis further activates ASIC1, which } \\
\text { precedes neuroinflammation and other autoimmune phe- } \\
\text { nomena. A decrease in the CNS pHi opens ASIC1, which, } \\
\text { through the stimulation of } \mathrm{Ca}^{++} \text {into neural cells, induces } \\
\text { axonal injury, apoptosis, demyelination in MS and } \beta \text {-amy- } \\
\text { loid accumulation in AD. }\end{array}$ & {$[45,46]$} \\
\hline $\begin{array}{l}\text { Ion channels (IOs) in } \\
\text { cancer pathogenesis }\end{array}$ & $\begin{array}{l}\text { Different ion channels (IOs) are involved in the deregula- } \\
\text { tion of the pHi/pHe system in cancer cells, stimulating cell } \\
\text { proliferation, matrix invasion, resistance to apoptosis and } \\
\text { metastatic potential. Hv1 and/or Nav1.5 have been found } \\
\text { to be highly expressed in highly invasive BC cells but not } \\
\text { in poorly invasive BC cells. }\end{array}$ & {$[10,11,47-53]$} \\
\hline
\end{tabular}




\begin{tabular}{|c|c|c|}
\hline $\begin{array}{l}\text { Acidosis and } \\
\text { immunity }\end{array}$ & $\begin{array}{l}\text { Acidity of the tumor microenvironment (TME) disrupts } \\
\text { the body immune defense mechanisms towards malig- } \\
\text { nant tumors, locally and systemically. This allows a relent- } \\
\text { less and uncontrolled tumor progression. Neutralizing tu- } \\
\text { mor EC acidity with alkaline solutions improves the im- } \\
\text { mune response. }\end{array}$ & [54-58] \\
\hline $\begin{array}{l}\text { Human growth factor } \\
\text { (GFs) abnormalities in } \\
\text { HNDDS and cancer }\end{array}$ & $\begin{array}{l}\text { Removal of essential GFs result in apoptosis. NHE activity } \\
\text { is fundamental in the } \mathrm{pH} \text { regulation of the CNS, } \\
\text { normalizing neural homeostasis by stimulating cellular } \\
\text { meta-bolism and DNA synthesis. PRGF has been shown } \\
\text { to induce an important decrease in brain amyloid- } \beta(\mathrm{A} \beta) \\
\text { deposition and tau phosphorylation in a mice model of } \\
\mathrm{AD} \text {, also reducing inflammatory responses and } \\
\text { promoting } \mathrm{A} \beta \text { degradation. }\end{array}$ & {$[6,7,26,59-64]$} \\
\hline $\begin{array}{l}\text { Mitochondriopathy in } \\
\text { MS and HNDDs. }\end{array}$ & $\begin{array}{l}\text { Mitochondrial dysfunction has been considered to } \\
\text { represent a significant etiopa-thogenic factor in the } \\
\text { pathogenesis and progression of several HNDDs. } \\
\text { Mitochondria also play a crucial role in oligodendrocyte } \\
\text { differentiation. Any perturbation in mitochondrial } \\
\text { function is likely to damage myelinogenesis and worsen } \\
\text { the evolution of MS. }\end{array}$ & [65-70] \\
\hline $\begin{array}{l}\text { Microbiota in the } \\
\text { etiopathogenesis of } \\
\text { HNDDs and MS }\end{array}$ & $\begin{array}{l}\text { Gut dysbiosis increases intestinal permeability and } \\
\text { impairs Treg cells function, leading to inflammation and } \\
\text { oxidative stress }\end{array}$ & {$[71,72]$} \\
\hline
\end{tabular}

\subsection{On pH-related etiology and pathogenesis of cancer in the post Warburg era.}

Basic and clinical research into the regulation and deregulation dynamics of the hydrogen ion $\left(\mathrm{H}^{+}\right)$, the intracellular $\mathrm{pH}$ (i.c. or $\mathrm{pHi}$ ) and extracellular (e.c. or pHe), in health and disease, has grown at an increasingly fast rate since the 1970's in many areas of medicine and science. While the dynamics of the hydrogen ion $\left(\mathrm{H}^{+}\right)$, initially interested the realm of physiology, other areas of medicine, mainly oncology and neurology, were progressively included within this new and integral perspective $[4,6,9,10]$.

Lately, the study of the dynamics of the $\mathrm{H}^{+}$in medical research, mainly in cancer, has been extended sideways to include from the field of theoretical physics [73] to, most recently, even the pathogenesis of schizophrenia [74]. This contribution also aims to revive and actualize these classical seminal concepts on systemic homeostasis and physiopathology in order to apply them to the fields of neurology and oncology, but now at a cellular and microenvironmental level. These concepts will be mainly focused upon the etiopathogenesis of human neurodegenerative diseases (HNDDs), mainly of multiple sclerosis (MS), and their links and differences with cancer, all in order to implement new therapeutic possibilities in both areas based upon an integral and homeostatic perspective.

Regarding the cancer situation, complete listings of metabolically-oriented anticancer medications have been published by our group [4]. In that seminal publication on cancer and neurodegeneration, the emphasis rested on cancer treatment. In the present 
contribution, the main emphasis will rest on a metabolic approach to the etiopathogenesis and treatment of neurodegenerative diseases, with a special emphasis on MS.

Nowadays, the prime cause of cancer is no longer recognized to be the aerobic glycolysis of tumors, as Otto Warburg defended all his life. Instead, all the latest evidence indicates that the 'prime' cause of cancer and the fundamental and sine qua non carcinogenic factor behind the induction of the aerobic glycolysis initially described by Warburg [4,32], is a selective pathological alkalization of cells in all malignant tumors and leukemias as induced by a wide array of mediating factors [32,40]. The upregulation of the $\mathrm{Na}^{+} / \mathrm{H}^{+}$exchanger isoform 1 (NHE1) has been demonstrated to be the main etiologic factor in oncogene-driven neoplastic transformation. In this case, the activation of NHE1 stimulates proton $\left(\mathrm{H}^{+}\right)$extrusion, with a resultant microenvironmental intracellular alkalization and extracellular acidification [33-35]. Intracellular alkalization also appears as the primary driver of many other cancer hallmarks, including aerobic glycolysis, DNA synthesis and tumor growth among them $[33,36]$. This high $\mathrm{pHi} / \mathrm{low} \mathrm{pHe}$ situation creates a cancer-selective and pathognomonic reversed $\mathrm{H}^{+}$gradient, also known as cancer proton reversal (CPR), which is mediated by this highly pathological de regulation of $\mathrm{H}^{+}$dynamics in all malignant cells and tissues $(\uparrow \mathrm{pHi} / \downarrow \mathrm{pHe})[34,37,38,75]$ (Figure 1$)$.

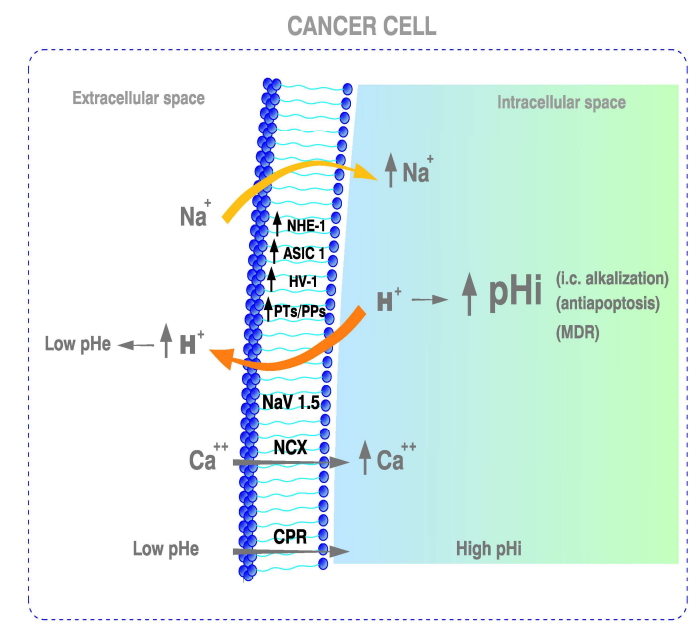

Figure 1. Metabolic characteristic of cancer cells. Intracellular alkalination of multiple upstream causes becomes the universal mediator of malignant transformation and the main metabolic and acid-base antiapoptotic factor, which is also fundamental in MDR and chemotherapy. Its secondary interstitial acidification of tumors (CPR) drives the following cascade of steps of the metastatic process. NHE-1: $\mathrm{Na}^{+} / \mathrm{H}^{+}$antiporter isoform 1 ; ASIC-1 Acid-sensing Ion channel, type 1a; $\mathrm{HV}-1$ : Voltage-gated $\mathrm{Na}^{+}$and $\mathrm{H}^{+}$channels, isoform 1; PTs: Proton transporters; PPs: Proton pumps; Nav 1.5: Voltage-gated sodium channel isoform 1.5; NCX: $\mathrm{Na}^{+} / \mathrm{Ca}^{2+}$ exchanger; CPR: Cancer proton reversal; MDR: multiple drug resistance. (For further details: see text). 


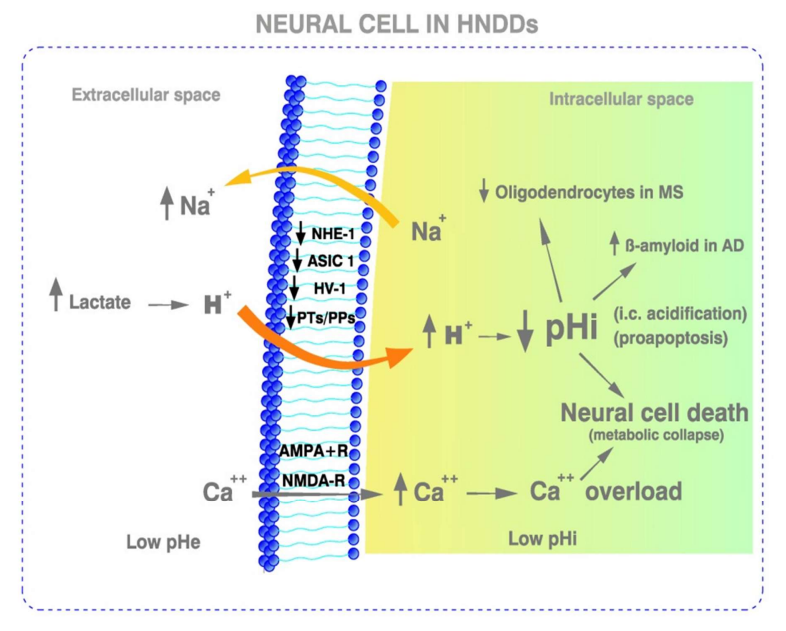

Figure 2. Metabolic characteristics of HNDDs. The downregulation of NHE1, ASIC1, Hv-1 and/or proton transporters. together with a toxic intracellular $\mathrm{Ca}^{++}$overload produce further deviations towards acidification of neural cells. This is followed by activation of proteolytic cascades in neurons. Such a $\mathrm{Ca}^{++}$overload can be also mediated by an excessive release of glutamate leading to the over-activation of the glutamatergic excitatory NMDA receptors. An opposite situation takes place in HNDDs that in cancer cells regarding the pHi of cells. The low pHe in HNDDs can be secondary to an intracellular acidosis of a metabolic origin (metabolic/aerobic acidification) and/or to an acidosis related to a lack of oxygen (hypoxic/ischemic/anaerobic acidosis). HNDDs: human neurodegenerative diseases; AD: Alzheimer's disease: MS: Multiple sclerosis; NHE1: $\mathrm{Na}^{+} / \mathrm{H}^{+}$exchanger isoform 1; Proton-gated acid sensing ion channel, isoform 1; ASIC-1; Acid-sensing Ion channel type 1a; Hv1: Voltage-gated proton channel type 1; Nav1.5: Voltagegated sodium channel isoform 1.5; PTs: Proton transporters; PPs: Proton pumps; NCX: $\mathrm{Ca}^{++} \mathrm{Na}^{+}$exchanger; CPR: Cancer proton reversal. AMPA-R: $\alpha$-amino-3-hyroxil-5-methyi-4-isoxazolepropionic acid receptor; NMDA-R: N-methyl-d-aspartate receptor. (For further details, see text).

Furthermore, it has been shown that proton $\left(\mathrm{H}^{+}\right)$efflux, on its own, induces dysplasia and potentiates cancer cell growth and invasion by oncogenic Ras. On the contrary, inhibiting $\mathrm{H}^{+}$efflux induces cell death in invasive tumor cells lines $[32,39,76]$. Highly important are the outstanding results obtained by the group of Fliegel, who has shown that NHEmediated $\mathrm{H}^{+}$extrusion by itself has a direct carcinogenic effect on breast cells [41,42]. In these studies, NHE1 hyperactivity appears to be an early and decisive driver in breast cancer (BC) carcinogenesis [36]. Further, an H+ efflux-driven increase in pHi induces the in situ progression from precancerous lesions to invasive BC [43]. In summary, all this evidence further indicates that $\mathrm{H}^{+}$efflux is the main transforming factor in metabolic carcinogenesis [34,37,38,75] (Table 1 and Figure 1). Finally, while NHE1 upregulation and its extracellular consequences (low $\mathrm{pHe}$ and $\mathrm{CPR}$ ) indicates that $\mathrm{H}^{+}$is the fundamental mechanism behind a high $\mathrm{pHi}$-driven tumor growth and metastatic progression, similar $\mathrm{pH}$ changes can also be mediated by other membrane-bound proton transporters (PTs), like monocarboxylate transporters (MCTs), acid-sensing ion channel type 1 (ASIC1) and proton pumps (PPs) [44,77-84] (Figure 1).

\subsection{Molecular, biochemical, metabolic and genetic links and differences between neurodegeneration and cancer.}

While one of the main hallmarks of all malignant tumors is now recognized to be the selective PCR described above [4], HNDDs systematically show a strong tendency towards a pro-apoptotic acidification of the $\mathrm{pHi}$. This is the opposite of the cancer situation and is the main and all-pervasive metabolic difference with all cancers, from solid tumors or leukemias. Therefore, what can be therapeutic for cancer - the induction of a selective 
and proapoptotic $\mathrm{pHi}$ acidification -, should be damaging to HNDDs (Table 1 and Figures 1 and 2). Furthermore, this dynamic pHi-centric perspective leads to a new and integral paradigm and to a unified $\mathrm{pH}$-related theory of the apoptosis-antiapoptosis machinery mediated by the intracellular/extracellular hydrogen ion dynamics and its secondary prodeath and anti-death mechanisms. Interestingly, epidemiological studies have shown that Alzheimer's disease and cancer present an inverse association among them, once again indicating the opposed tendency of these two situations [85].

Other different perspectives linking cancer and neurodegeneration, like the genetic mutation theory, have concluded that, while both processes share some genes and molecular mechanisms, they do it in opposite ways [86-88]. The genetic approach proposes that somatic mutations and DNA damage are to be blamed for the disruption of the genetic homeostasis of cells populations in both cancer and HNDDs [89]. Further, different genetic factors, like the inheritance of mutated genes, have been proposed to facilitate the onset of cancer and neurodegeneration [87,90].

However, the genetic, immune and metabolic approaches do not exclude each other. On the contrary, it seems possible that they can be integrated and, to a certain point, unified, following Nijhout's metaphor: "When a compound codified by a gen is needed, it is a signal from the environment which activates the expression of the gen and never an intrinsic characteristic of the gen". Indeed, the fact that genetic deregulations need mediating metabolic pathways to induce a certain damage has been repeatedly shown in the cancer context in different situations, like $\mathrm{Na}+\mathrm{H}+$ upregulation mediating different carcinogenic oncogens and viruses $[33,91,92]$. These have also been found in certain cancer situations that have unified genetic factors with $\mathrm{pH}$ abnormalities and NHE deregulation in leukemias. Similarly, the integration of $\mathrm{pH} / \mathrm{NHE}$-related etiopathogenesis of certain lymphomas with immune parameters has also been reported (48). The question that still remains is to find similar specific cause-effect relationships among genetic deregulations, metabolic consequences and immune disturbances in HNDDs processes.

\subsection{Multiple sclerosis (MS) as an excellent model for the study of HNDDs. The million-dollar question on the etiopathogenesis of MS is: what comes first, immune or metabolic malfunctioning? Further parallelisms and differences with cancer.}

MS is a disabling disease of unknown etiology where the protecting layers of peripheral nerves, the spinal cord and the brain are affected. The capricious and sometimes unpredictable evolution of MS induces a myriad of multiorganic symptoms from its two main forms, the relapsing type or the steadily progressive type. In all cases, its evolution gets progressively worse as the disease advances, creating increasing disabilities, and many times shortening the patient's life.

During the last few years, many methods have been tried to improve the understanding of the essential nature of MS, as well as its prognosis and therapy. Nowadays, it is generally accepted that the fundamental nature of MS rests on a disorder of the immune system, with a secondary destruction of nerve sheaths through an apoptosis-dependent demyelination process [93].

As compared to other HNDDs, there is no doubt that immune abnormalities are most significant in the pathogenesis of MS. Since to date there is no cure for MS, other alternative approaches to this disease and the rest of HNDDs are necessary. Recently, B cell-depleting monoclonal antibodies, like the anti-CD20 agent ocrelizumab, have shown a significant effect against MS, both in the relapsing form of the disease and, perhaps to a lesser degree, in slowing the relentless advance of the primary progressive form [94,95]. During te few years, such frustration has even prompted a questioning and some doubts on the immunological origin of MS [96].

An acidic pHe, as in all malignant tumors, is also a fundamental characteristic of the demyelinating lesions in MS and also in other HNNDs (Table 1 and Figure 2). While an acidic pHe decreases the migration, proliferation and survival of oligodendrocyte precursor cells, the fundamental effect seems to be that it also reduces their differentiation into 
mature oligodendrocytes, thus contributing to demyelination while hindering remylination $[15,97]$.

It is becoming increasingly recognized that metabolism and immunology are inextricably linked. Cellular metabolism leads immune cells to adopt different functions that depend of the state of the microenvironment, this determining cellular life or death [98]. In cancer, the tumoral microenvironment is fundamental in regulating antitumor immunity, where its characteristic pHe acidification allows tumors to escape the antitumoral immune response of the organism. In this situation, the final result of that intratumoral-interstitial (EC) low $\mathrm{pHe}$ is to create a protective shield around, and within, malignant tumors, leading to a state of immunosuppression mediated by a low pHe-induced loss of function of T and NK cells [54,55]. On the contrary, neutralizing the tumor EC acidity with alkaline solutions improves the antitumor responses to immunotherapy [56-58].

In the same oncological line, Marches et al., showed the cause-effect relationship between metabolism and immunity by demonstrating that the anti-IgM-mediated induction of cell death in human B lymphoma cells (the immune approach) is secondary, and dependent on, the inhibition of the sodium-hydrogen exchanger (NHE1) and an early pHi acidification (the metabolic approach). Most importantly, these data allow the unification of two apparently far-apart fields of research, metabolism and immunity, under one wideranged embracing unit: the, so called, immunometabolism" [99]. This perspective indicates that the immune anti-IgM treatment depends on, and is secondary to, a metabolic NHE1-controlled pHi and that the inactivation of the NHE1 in anti-IgM-stimulated cells results in a cellular acidification that triggers apototic cell death. The conclusion is that, at least in these situations, metabolic changes precede immunological ones [16,100]. Perhaps, the term "immunometabolism" should be better replaced, at least in such situations, by "metabolic immunity", depending on which one of the two mechanisms is first at work $[101,102]$.

Apart from the above considerations on the cause-effect interelationships between metabolic and immunological disfunctions, we initially showed the close links, both similarities and differences, between cancer and neurodegeneration at multiple levels, from basic research to clinical therapeutics [4,6,7]. Finally, in all the above-considered cases, metabolic abnormalities appear to preceed immunological malfunctioning and cellular damage ("metabolic immunology" or "immunology metabolism-dependant").

\subsection{Cellular and microenvironmental acid-base abnormalities in neurodegenerative diseases (Box 1).}

In order to maintain neuronal excitability, synaptic transmission and neurotransmission in the CNS, the organism needs to keep their i.c and e.c. microenvironmental acidbase homeostasis within very narrow limits [103,104]. A pathological lowering of $\mathrm{pH}$ takes place not only in MS but also in other HNDDs, where $\mathrm{Ca}^{++}$overload can further promote i.c. acidification to induce neuronal proteolysis and apoptosis [105,106] (Figure 2). Such an acidified intra and extracellular $\mathrm{pH}$ is also pathognomonic of Alzheimer's disease (AD), amyotrophic lateral sclerosis (ALS) and Huntington's Disease (HD), and is fundamental in the progression of these and other HNDDs [8,10-14]. A low pHi and pHe rapidly decreases neuronal transmission and activity, preceding the onset of neural cell death by apoptosis [17-21], the same as ASIC1 does [22]. In the same vein, accumulation of $\beta$-amyloid $(\beta A)$ is directly induced by acidosis [11-14,16-22,104,106,107] (Figure 2 and Box 1). Further, low neural cell pHs induce protein aggregation, mitochondrial dysfunction, oxidative stress and neuroinflammation, which are hallmarks of Parkinson's disease (PD) [23]. The low pHe in PD and other HNDDs can be secondary, either to an i.c. acidosis of a metabolic origin (metabolic/aerobic acidification) and/or to an acidosis related to a lack of oxygen (hypoxic/ischemic/anaerobic acidosis) [23]. Finally, at least in ALS, i.c. acidification-mediated apoptosis is secondary to a $\mathrm{Ca}^{++}$-dependent effect, a pathogenetic mechanism considered to be responsible for disease progression [21,108] (Box 1). 
1.5. Acid-base dynamics and homeostasis as the main factor that allows to reach a better understanding of the intimate nature of HNDDs and cancer. Multiple sclerosis as a fundamnetal basic linking model.

Intracellular acidification is more pronounced in the brain of AD patients [11,107], while $B A$ aggregation in a mice model of $\mathrm{AD}$ is induced by acidosis and reverted upon microenvironmental alkalization, just as happens when using plasma rich in growth factors (PRGF) [16,21,24-26]. Lowering pHi of neurons from 7.36 to 7.09/7.00 through exposure to nitric oxide (NO) sets in motion a programmed cell death program, increasing DNA fragmentation and decreasing cell survival ("low pHi-mediated metabolic collapse") [7,8,11,27-29]. This low $\mathrm{pHi}$ and low $\mathrm{pHe}$-mediated apoptosis results from the activation of three low pHi-dependent caspases and endonucleases [30,31]. Thus, maintaining a strict and narrow range of $\mathrm{pHi} / \mathrm{pHe}$ homeostasis in the CNS becomes mandatory in neural protection, since acid-base parameters control a myriad of neuronal functions, like excitability, synaptic transmission, neurotransmitter uptake, intercellular communication, nociception and inflammation $[7,8,11,27,28]$. Altogether, these data indicates that NO and caspase inhibition are theoretically indicated in AD, MS and also in other HNDDs [30,31] (sections 2.11 and 2.15) (Box 2).

Box 2. Metabolically-based therapeutic options based upon the similarities and differences among cancer and neurodegeneration. MS: Multiple sclerosis; HNDDs: Human neurodegenerative diseases; PD: Parkinson's disease; ASIC1: Acid-sensing Ion channel type 1a; Hv1: Voltage-gated proton channel type 1.5; Nav1.5: Voltage-gated sodium channel isoform 1.5; GFs: Growth factors; PRGF: Plasma rich in growth factors. 


\begin{tabular}{|c|c|c|}
\hline Mechanism & Therapeutic options & References \\
\hline $\begin{array}{c}\text { Ion channels/ASIC } \\
\text { inibitors }\end{array}$ & $\begin{array}{l}\mathrm{NaV} 1.5-\mathrm{Na}^{+} \text {channels associates with NHE- } 1 \text { to be } \\
\text { overexpressed in breast cancer, stimulating the } \\
\text { formation of invadopodia and the metastatic } \\
\text { process. The utilization of voltage-gated IO- } \\
\text { inhibiting drugs has been shown to increase survival } \\
\text { in cancer patients. They are also indicated as a } \\
\text { therapeutic option in MS and HNDDs. }\end{array}$ & {$[50,109,110]$} \\
\hline $\begin{array}{l}\text { Amiloride (AM), and its deriva- } \\
\text { tives: liposomal amiloride, ben- } \\
\text { zamil and bepedril }\end{array}$ & $\begin{array}{l}\mathrm{AM} \text { is a non-specific and weak NHE inhibitor and } \\
\text { cell acidifier that has been recommended in both MS } \\
\text { and cancer. In MS, as well as in other HNDDs, AM } \\
\text { is also recommended as a preventive measure, AM } \\
\text { acts as an NHE, } \mathrm{Ca}^{++} / \mathrm{Na}^{+} \text {exchanger and ASIC } \\
\text { inhibitor. Paradoxically, since AM is a cell acidifier, } \\
\text { it has been shown to have protective effects in } \\
\text { different neurodegenerative situations by } \\
\text { preventing the acidosis-induced cellular Ca+ injury, } \\
\text { also preserving myelin in hypoxic and inflammatory } \\
\text { conditions. Bepridil, a more powerful NHE inhibitor } \\
\text { than AM, also acting as an ASIC1 inhibitor, has been } \\
\text { reported to protect myelinated axons from } \\
\text { degeneration. }\end{array}$ & {$[6,8,11,30,59,103-105,111-129]$} \\
\hline Cariporide (CP) & 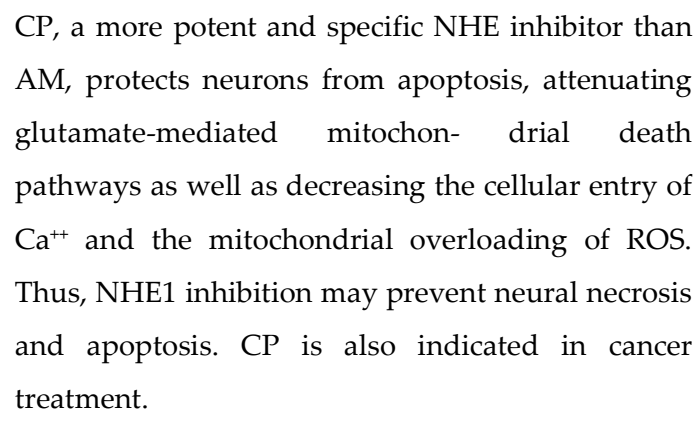 & {$[111,130]$} \\
\hline $\begin{array}{l}\text { Other anti-MS drugs: Amino- } \\
\text { pyridine (4-AP), nafamostat } \\
\text { mesylate (NM) and butyrate. }\end{array}$ & $\begin{array}{l}\text { 4-AP works as a potassium } \mathrm{K}^{+} \text {channel blocker and } \\
\text { it is clinically approved to treat walking deficiencies } \\
\text { in patients with MS. It helps to improve nerve con- } \\
\text { duction induced by demyelination. NM has been } \\
\text { tried in cancer patients but not in MS or HNDDs. }\end{array}$ & [131-136] \\
\hline
\end{tabular}




\begin{tabular}{|c|c|c|}
\hline Butyrate & $\begin{array}{l}\text { In MS, butyrate protects the intestinal barrier, } \\
\text { increases Treg cells population, reduces pro- } \\
\text { inflammatory T-lymphocytes and facilitates the } \\
\text { differentiation of oligodendrocytes, besides } \\
\text { suppressing demielyination and enhancing } \\
\text { remyelination. }\end{array}$ & [134-136] \\
\hline $\begin{array}{l}\text { PTIs and human growth factors } \\
\qquad(\mathrm{hGF})\end{array}$ & $\begin{array}{l}\text { Different growth factors (GFs) have been tried for } \\
\text { neuronal protection in different HNDDs. Platelet- } \\
\text { derived growth factors (PRGF) have been most suc- } \\
\text { cessful in AD and PD models in rodents. They are } \\
\text { bound to be an important part of the clinical arma- } \\
\text { mentarium in MS and other HNDDs. }\end{array}$ & {$[26,137-141]$} \\
\hline Human growth hormone (hGH) & $\begin{array}{l}\text { GH plays a very important role in the development } \\
\text { and maintenance of brain functions. The brain has } \\
\text { been considered to be a GH-target tissue. Moreover, } \\
\text { there is a production of GH and its receptor in neural } \\
\text { stem cells, where the hormone induces their } \\
\text { proliferation and differentiation. In rats, GH } \\
\text { administration induces neural cell proliferation and } \\
\text { recovers motor function after frontal cortex lesions. } \\
\text { GH induces the expression of a number of } \\
\text { neurotrophic factors. In humans, hGH } \\
\text { administration improve cognition, learning and } \\
\text { memory in different pathologies. GH administration } \\
\text { in rat AD models improves spatial cognition. The } \\
\text { possible usefulness of hGH in AD in humans has } \\
\text { been postulated. In mice models of ALS, GH plays a } \\
\text { protective effect on motor neurons, increasing } \\
\text { survival times and improving motor performance. } \\
\text { GH concentrations are low in the CSF of ALS } \\
\text { patients, but its administration has no effect on the } \\
\text { clinical progression of this fatal HNDD. }\end{array}$ & [141-157] \\
\hline
\end{tabular}




\begin{tabular}{|c|c|c|}
\hline Melatonin (MT) & $\begin{array}{l}\text { MT can prevent the NO stress-induced } \\
\text { mitochondrial dysfunction in experimental models } \\
\text { of AD. In mouse models of AD, there is a significant } \\
\text { clinical improvement after chronic MT treatment } \\
\text { with an improvement of cognition and memory as } \\
\text { well as a reduction of the deposits of A } \beta \text {. MT } \\
\text { administration at pharmacological dosages should } \\
\text { be considered in the adjuvant treatment of certain } \\
\text { HNDDs like MS. MT seems to improve intestinal } \\
\text { and adipose lipid metabolism in experimental MS } \\
\text { and seems to improve the progression of the disease. }\end{array}$ & {$[148,158-163]$} \\
\hline Nitric oxide (NO), inhibitors. & $\begin{array}{l}\text { Nitric oxide synthase (iNOS) is increased in MS pa- } \\
\text { tients, supporting MS pathogenesis, manly inhibit- } \\
\text { ing the mitochondrial respiratory chain. Agmantine } \\
\text { is a NO inhibitor that shows activity against MS in } \\
\text { vivo, and it should be considered within the integral } \\
\text { treatment of MS. Also, hydralazine decreases the ac- } \\
\text { cumulation of LA and is a promising drug in the } \\
\text { complementary treatment of MS. }\end{array}$ & [164-175] \\
\hline $\begin{array}{l}\text { Mitochondrial booster agents in } \\
\text { MS: methylene blue (MB), alpha } \\
\text { lipoic acid ( } \alpha \text {-LA) and } \\
\text { fermented wheat germ extract } \\
\text { (FWGE). }\end{array}$ & $\begin{array}{l}\text { MB restores mitochondrial function and has a role in } \\
\text { the treatment of MS. However, in spite it also is a NO } \\
\text { inhibitor, it has not shown activity against MS. } \\
\text { FWGE is a potent mitobooster agent, restores mito- } \\
\text { chondrial activity, also suppresses the Warburg ef- } \\
\text { fect and decreases the lactic acid (LA) burden in } \\
\text { MS. So far, however, its utilization has been reported } \\
\text { mainly in the cancer context. }\end{array}$ & [176-180] \\
\hline $\begin{array}{c}\text { Calcium }\left(\mathrm{Ca}^{++}\right) \text {entry inhibitors } \\
\text { in MS. }\end{array}$ & $\begin{array}{l}\text { An excess of i.c. } \mathrm{Ca}^{++} \text {increases ROS, interferes with } \\
\text { neurotransmission and neuroinflammation, } \\
\text { promotes further i.c. acidification, favors apoptosis } \\
\text { and leads to the development of MS. } \\
\text { Administration of } \mathrm{Ca}^{++} \text {inhibitors represents a } \\
\text { fundamental neuroprotective measure in MS. } \\
\text { Several of these inhibitors are clinically available. } \\
\text { Bepridil also works as a } \mathrm{Ca}^{++} \text {channel blocker and } \\
\text { has shown to induce an outstanding improvement } \\
\text { of symptoms in the managing of MS in model } \\
\text { systems. }\end{array}$ & {$[16,22,181-190]$} \\
\hline
\end{tabular}




\begin{tabular}{|l|l|l|}
\hline Caspase-3 inhibitors in MS. & $\begin{array}{l}\text { Caspase inhibition is therapeutically indicated in } \\
\text { AD, MS and other HNDDs. Since caspase-3 pro- } \\
\text { motes pyroptosis (apoptosis-associated with a high } \\
\text { inflammatory component), suppressing pyroptosis } \\
\text { becomes a promising strategy in the management of } \\
\text { MS. }\end{array}$ & [30,31,191-193] \\
\hline Antilactacemics in MS. & $\begin{array}{l}\text { Antihyperlactacemics offer a new therapy to } \\
\text { minimizing myelin degeneration in MS. Among } \\
\text { them, alkaline preparations are important in the } \\
\text { treatment of MS since they have been shown to } \\
\text { relieve MS patients from ocular symptoms, tiredness } \\
\text { and muscle pain. They have been used in the cancer } \\
\text { context too. In combination with DMSO, sodium } \\
\text { bicarbonate has proved to be a safe and effective } \\
\text { treatment of pain in malignancy. Also, the use of oral } \\
\text { DMSO, has also been used in treating autoimmune } \\
\text { and ocular diseases. }\end{array}$ & [15,194] \\
\hline
\end{tabular}

\subsection{Ion channels activity in neurodegeneration and cancer.}

1.6.1. Ion channels activity in neurodegeneration.

Proton-gated acid sensing ion channels (ASIC), mainly the isoform ASIC1, favor an excessive intracellular accumulation of $\mathrm{Na}^{+}, \mathrm{Ca}^{++}$and $\mathrm{H}^{+}$in $\mathrm{MS}$ and other HNDDs, with the resulting severe neural damage secondary to $\mathrm{Ca}^{++}$overload and acidification-mediated apoptosis [45,46] (Figure 2). Other channel blockers inhibit T-cell activity, once again placing metabolic changes before immune or autoimmune ones [195]. These ASIC1-mediated metabolic abnormalities induce axonal degeneration in the CNS of mice, further showing that tissue acidosis, which also activates ASIC1, precedes the onset of neuroinflammation and other autoimmune phenomena [58,117].

In the same vein, i.c. $\mathrm{H}^{+}$concentration determines neuronal excitability through ion channel activity [104]. The higher the $\mathrm{H}^{+}$concentration, the lower the $\mathrm{pHi}$ and the excitability. A decrease in the CNS pHi opens ASIC1, which, through the stimulation of $\mathrm{Ca}^{++}$ into neural cells, facilitates axonal injury, the induction of apoptosis, and most importantly, demyelination in MS and $\beta$-amyloid accumulation in AD [104,117] (Figure 2). Spontaneous neurotransmitter release and neuromuscular transmission are reduced by ASIC1 activation at motor nerve terminals, effects that are reproduced by acid solutions [22]. Furthermore, ASIC1 activity induces autoimmune inflammation in the CNS, besides axonal degeneration, once again placing metabolism before immunity [58]. In both the CNS and the neural peripheral system, the activation of $\mathrm{Ca}^{++}$-permeable channels during acidosis exacerbates neurodegeneration in mice [20]. ASIC1 activity has been recognized in many pathologies of the CNS, such as MS, Huntington's disease (HD) and Parkinson's disease (PD), making them a target for therapy [196]. On the contrary, neural cells lacking ASIC are resistant to acid injury [10]. Finally, NaV1.5 $\mathrm{Na}^{+}$channel is also involved in regulating endosomal acidification [197] (Box 2).

\subsubsection{Ion channels activity in cancer.}

Different ion channels (IOs) are involved in the disregulation of $\mathrm{pHi} / \mathrm{pHe}$ in cancer cells and, in this way, in stimulating cell proliferation and adhesion, motility, extracellular 
matrix invasion, resistance to apoptosis and metastatic potential [10,11,47-52]. Consequently, IOs have been proposed as a potential target for anticancer therapy and as a new hallmark for cancer [47-52,198-201]. On the contrary, cellular acidification, which is the ultimate driver of the clinical picture of certain HNDDs, has been shown to be highly deleterious in neurodegeneration also through $\mathrm{pH}$-disregulating IOs [6,8,10,11] (Figure 2 and Box 1).

There is also a group of voltage-gated $\mathrm{Na}^{+}$and $\mathrm{H}^{+}$channels $(\mathrm{Hv})$ whose activation results in the extrusion of the excess intracellular $\mathrm{H}^{+}$and, therefore, participates in the acidification of the extracellular compartment [202]. Hv1 and/or Nav1.5 were found to be highly expressed in highly invasive BC cells but not in poorly invasive BC cells [53]. Thus, their therapeutic down-regulation reduces BC cell migration, invasion, tumor size and clinical stage, all because of the induction of an i.c. acidification [203-205], HV1 also being an important factor favoring the CPR of cancer cells Figure 1).

\subsection{Human growth factor (GFs) abnormalities in neurodegeneration and cancer.}

A deficiency of certain human growth and trophic factors (GFs) is directly involved in the pathogenesis of several HNDDs. Different animal and human studies have linked cognitive deficits with changes in brain and peripheral trophic factors [206]. Removal of essential GFs result in apoptosis [60]. The deficiency of different GFs is a general characteristic of HNDDs that is involved in symptoms like the lack of tropism and mobility of these HNDDs [61]. Since NHE1 activity is fundamental to the $\mathrm{pH}$ regulation of the CNS [59], different GFs, platelet-derived (PDGF) or otherwise, also normalize neural homeostasis by stimulating cellular metabolism and DNA synthesis [62-64] (Box 2).Therapywise, a wide array of GFs, platelet-derived (PDGF) or otherwise, activate NHE [62,63]. The use of plasma rich in growth factors (PRGF) has been shown to induce an important decrease in brain amyloid- $\beta(A \beta)$ deposition and tau phosphorylation in a mice model of $\mathrm{AD}$, also decreasing astrocyte reactivity and synaptic loss while reducing inflammatory responses, finally promoting $\mathrm{A} \beta$ degradation [26].

In both hypotrophic or normal situations, GFs increase the pHi, stimulates cellular metabolism and DNA synthesis, but also may have a direct carcinogenic effect $[64,111,207]$. Direct therapeutic possibilities arise from these pathogenetic associations, suggesting that the use of GFs can improve the therapeutic armamentarium of certain HNDDs $[62,208,209]$. Some authors have studied the activity or deficiency of different GFs in HNDDs, as well as their relationships to i.c and e.c. acid-base homeostasis, all within the wide ranged concept of "the trophic factor withdrawal syndrome" (TFWS) [6,7] (Figure 2).

Initially departing from the seminal homeostatic concept, these data further contribute to open new and promising areas of regenerative treatment in HNDDs It can be concluded that the therapeutic failure in the prevention and treatment of MS and other HNDDs can be to a great deal secondary to the scarce information about the specific role of the different GFs factors in the pathogenesis of the TFWS [6,7]. Thus, all therapeutic efforts should be directed to maintain neural i.c and e.c. acid-base homeostasis within a very narrow physiological range. This would prevent the metabolic collapse induced by neural cell acidification and $\mathrm{Ca}^{++}$entry, as well as their secondary activation of cell death programs, either in MS and/or other HNDDs.

\subsection{Mitochondriopathy in MS and other human neurodegenerative diseases (HNDDs).}

The highlighted interplay of mitochondrial dysfunction, hypoxia, acidification, and inflammation is a relevant issue in MS and other HNDDs [4,23,210,211].

Mitochondrial dysfunction has been considered to represent a significant factor in the etiopathogenesis and progression of ALS, AD, PD, and HD [212]. Several lines of evidence suggest that mitochondrial dysfunction may be crucially involved in the pathogenesis of ALS [66]. All the evidence indicates that mitochondrial disease, either as a primary 
cause or as a contributing factor, should become an important target for therapeutic intervention in different HNDDs [213,214]. All in all, and in spite all the accumulated evidence available, it can be said that the fundamental role of acidification in the onset and progression of HNNDs has been hughly underestimated [215].

Different mechanisms are involved in impaired mitochondrial function. These include free radicals, mitochondrial inducible NO synthase activity and NO production, $\mathrm{pH}$ changes, a disrupted electron transport system, oxidative stress, and abnormal mitochondrial permeability [67]. Therefore, a mitocondriopathy should be firmly considered in the pathogenesis and treatment of MS [67]._It is known that myelinogenesis is highly damaged during different periods of MS. This process, whether it takes place in the peripheral nervous system (Schwann cells and neurolemocytes) or the central nervous system (oligodendrocytes), is tightly associated with mitochondrial dynamics $[68,69]$. Therefore, any perturbation in mitochondrial function is likely to damage myelinogenesis and worsen the evolution of MS.

Neuroinflammation is another crucial characteristic to define MS pathology. Different cytokines are involved in it, such as IL-4, IL-10, IL-17, and TNF- $\alpha$ [216]. Furthermore, stimulation of microglia and macrophages with release of free radicals (e.g., reactive nitrogen species (RNS) and/or reactive oxygen species (ROS), leads to mitochondrial damage by upregulating cellular death pathways. Also, the mitochondrion plays a crucial role in oligodendrocyte differentiation [70]. Thus, restoring and/or stimulating mitochondrial function may result in remyelination and improve the evolution of MS.

\subsection{The Role of Lactate in MS.}

It had been shown that serum lactate (LA) measurements are higher in MS patients as compared to normal people. LA levels also become elevated with disease activity, progression or during relapses [217] (Figure 2). Cerebrospinal fluid (CSF) LA concentrations show a close link between MS plaque activity and LA metabolism [218]. Despite that the origin of these metabolic abnormalities is unknown, LA has been considered a biomarker of mitochondrial deregulation and an worsening agent in neuroinflammation [219-226]. However, an apparent contradiction arises because the increased secretion of LA during exercise is associated with improving vasculature [67]. This would decrease hypoxia, which is also one of the critical factors associated with MS through a hypoxia-inflammation vicious cycle [227]. It can be concluded that LA in MS should be carefully monitored, as it can even improve brain physiology through a "lactate-shuttle" [228], if it is taken into account that some brain tissues utilize LA as an alternative energetic fuel.

\subsection{The Role of Gut Microbiota in HNDDs and cancer.}

A most important and growing area on the links between neurodegeneration and cancer is the role of microbiota in neural disease etiopathogenesis. Studies conducted in recent years indicate that the composition of the human gut microbiota plays a fundamental role the etiopathogenesis of many diseases, including the development of HNDDs and cancer. Epidemiological studies have demonstrated that the composition of the intestinal flora can either facilitate or hinder the possibility of developing a HNDD or cancer. As a recent study shows, subjects developing Alzheimer's disease or Parkinson's disease will be somewhat protected against developing a malignant tumor and viceversa [72]. This antagonism does not affect genetic neurodegenerative disorders, such as Huntington's chorea or ALS, although in both diseases the composition of the intestinal flora is altered. This probably indicates that the affected nervous system also leads to gut dysbiosis, agreeing with the known relationships between gut and brain (the gut-brain axis) $[229,230]$.

In the case of cancer, as as in HNDDs, an increased intestinal permeability allows the entry of host bacteria and harmful metabolites produced by these bacteria, as well as some neurotransmitters and intestinal hormones. This cohort of abnormalities facilitates the 
onset and/+or progression of diverse non-genetic cancers. In summary, all the available data seem to indicate that gut dysbiosis is another important metabolic link between the development of HNDDs and cancer. What both kind of diseases share is the development of intestinal inflammation with a secondary damage of intestinal permeability and impaired Treg (regulatory T cell) function and immunity [72] (Box 1). Since both opposite pathologies have a similar departure point, at least in the case of non-genetic causes, the question that now arises is: what is the cause of the etiopathogenic differences between HNDDs and cancer regarding intestinal dysbiosis? A first approach to this question comes from a recent review by Hang et al [72]. These authors describe the effects of the six most frequent taxa of intestinal bacteria on the production of cancer or HNDDs and/or the improvement of each of these pathologies. After analyzing the results of several epidemiological studies, they conclude that while the predominance of anticancer bacteria (Bifidobacteria, Lactobacillus and Blautia), is higher in the gut of HNDDs as compared to normal individuals, the abundance of Prevotellaceae, Prevotella and Ruminococcaceae is higher in cancer than in normal subjects. However, although these evidences are well documented, there are many unsolved questions regarding the last mechanism responsible for the development of HNDDs or cancer. These come from the fact that both diseases share similar oxidative stress and inflammation. Therefore, which are the points where these mechanisms diverge in order to activate one and the other pathology?

\subsubsection{Gut microbiota and the immune system.}

A normal communication between gut microbiota and the immune system of the organism is key to maintain immunological homeostasis [231]. The maturation of T-cells in the intestine takes place in the gut lymphoid tissue. These T-cells can be developed into Treg, Th1, Th2, or Th17 cells by the action of antigen presenting cells and intestinal epithelial cells, but also by other metabolites as short chain fatty acids (SCFA) [232]. Treg cells are immune cells that play a key role in many autoimmune diseases, including MS, and the normalization of its activity seems to be very important for controlling MS.

Treg is dysregulated in gut dysbiosis, and the result of it is the activation of pathogenetic factors that produce pro-inflammatory cytokines and chemokines. However, Treg dysregulation also occurs in cancer. It is known that Treg can be differentially modulated by different bacterial taxa, and also by the presence of another important intestinal metabolite such as retinoic acid and its receptor. This might explain the activation of different cytokines, among them Il-6, depending on the pathogens responsible for gut dysbiosis. However, we still cannot explain that mitochondrial dysfunction, oxidative stress and inflammation exist not only in different HNDDs but also in cancer and how this relates to the differences in i. c. $\mathrm{pH}$ in both pathologies. (Figures 1 and 2). The possibility exists that this occurs by epigenetic mechanisms, but there is still no data that can demonstrate it. In fact, epigenetic changes modulate transcription of some genes linked to a specific Th cells lineage, consequently damaging chromatin structure and inducing different transcriptional competence of a gene [233].

\subsubsection{Neuroinflammation in MS.}

In MS there is a pro-inflammatory gene, Il-6, responsible for the activation of microglia and astrocytes and transportation of B and T lymphocytes into the brain. In addition, Il-7 gene, which also is a strong proinflammatory factor, plays a key role in the modulation of T lymphocytes [234]. Bacterial metabolites can cross the blood brain barrier (BBB) and activate toll-like receptor 4 which aggravates neuroinflammation and neurodegeneration. This is the case of a typical inducer of MS, the lipopolysaccharide (LPS) [235].

In general, the nature of MS is mostly considered to be an inflammatory autoimmune disease with some specials particularities, namely: A) it is a chronic neuroinflammation with infiltration of lymphocytes into the CNS; B) there is demyelination affecting nervous 
signals transmission, gliosis, axonal and oligodendrocytes damage, thisinducing a progressive neurological dysfunction [236].

Apart from some general factors such as a decreased in plasma vitamin D, smoking or sedentary life, which seem to be epidemiologically involved, there are other important factors that appear to be involved in MS development. As stated above, a very important product formed in the intestine when there is sufficient intake of vitamin A in the diet is retinoic acid (RA). Vitamin A is metabolized by intestinal epithelial cells producing RA. Then RA plays a critical role in tipping the balance from regulatory to inflammatory immune response. High concentrations of RA induce the differentiation of naive T cells into Treg cells, while at low concentrations RA is key for the production of proinflammatory cytokines, such as IFN-@) and IL-17A, by T helper 1 and 17 cells (Th1, Th17). These are needed for the inflammatory immune response to an infection [237,238]. From these and other studies it can be stated that an adequate production of intestinal RA is essential for a normal gut homeostasis and for the prevention of gut dysbiosis [239].

1.10.3. $\mathrm{pH}$ as an intracellular effector controlling differentiation of oligodendrocyte precursors (OPCs).

$\mathrm{pH}$ acts as a fundamental factor in controlling olygodendrocyte maturation via activation of the ERK1/2 in pathway in culture [240]. The optimal pHi for OPC differentiation is 7.15, a value at which astrocytes differentiation is strongly reduced. Conversely, acidic intracellular $\mathrm{pH}$ sharply interferes with the differentiation of OPC into mature oligodendrocytes, therefore decreasing the possibilities of myelination or remyelination. Finally $\mathrm{RA}$ increases OPC pHi, while preventing the alkalization that follows RA treatment completely abolishes OPC differentiation into mature oligodendrocytes, something that seems to depend mainly on the ERK1/2 signaling pathway and more pronounced when NHE1 activity is present, as observed in vascular smooth cells [241]. This pHi-dependent effect on differentiation has been observed in many other types of cells. From these basis it is likely that reduced gut RA production, occurring as a consequence of deficient vitamin $\mathrm{A}$ intake or gut dysbiosis contributes to the loss of myelin sheaths and absence of remyelination in MS, due to the lack of fully functional oligodendrocytes, together with the inflammation and oxidative stress above described. All in all, these considerations would also explain the acidic pHi in MS and other HNDDs.

\subsubsection{Gut microbiota and short-chain fatty acids in MS.}

Finally, gut microbiota digest dietary fibers to produce short-chain fatty acids (SCFAs), mainly acetate, propionate and butyrate [242]. Thse are mainly originated by anaerobic bacteria, such as Firmicutes. These SCFAs participate in the regulation of intestinal permeability and also in the regulation of immune responses. They cross the intestinal barrier and are able to reach the CNS, extensively modulating a wide array of physiological functions, such as mitochondrial function, neurotransmitter production, immune regulation and gene expression. Any significant alteration in the composition of gut microbiota leading to the decrease in the production of these SCFAs can be involved in the pathogenesis of several HNDDs, including AD, PD, MS, as well as other CNS diseases. The increased blood-brain barrier (BBB) permeability that results from the decrease of these SCFAs allows the entry into the brain of pro-inflammatory cytokines and reactive oxygen and nitrogen species (ROS/RNS) leading to over-activation of microglia and damage of the brain [243].

\section{2). On treatment. Metabolically and biochemically-derived preclinical and clinical treatment proposals in HNDDs. Therapeutic options.}

2.1. Therapeutic approaches and options to the pro-apoptotic metabolism of MS and HNDDs (Summary in Box 2). 
To counteract neural acid-base abnormalities, novel strategies for the prevention and treatment of HNDDs have been proposed, These measures consist in stimulatating cell metabolism through the use of a cohort of GFs and different hormones. The aim is to normalize i.c. and e.c homeostasis by: 1) Increasing neural pHi and pHe in HNDDs cells through the upregulation of dynamic buffering mechanisms, and 2) Prevent and/or correct an acidotic tendency through the activation of several alkalizing proton transporters (PTs), mainly the $\mathrm{Na}^{+} / \mathrm{H}^{+}$exchanger isoform 1 (NHE1), and proton pumps (PPs), [6$8,30,103,118-120]$. Indeed, there is no doubt on the essential function of the NHE1 in regulating the acid-base homeostasis of neurons. This indicates that the presence of an upregulated NHE1 is of paramount importance in the maintenance of neuronal pHi within healthy-homeostatic parameters. Among the different proton transporters, NHE1 appears to be the main mechanism that prevents neural cells to enter into a pathological decrease in $\mathrm{pHi}$ and $\mathrm{pHe}$ and, therefore, towards cellular death through cytosolic acidification $[8,59]$. However, other membrane-bound $\mathrm{H}^{+}$transporters and pumps also play an important role in this area $[18,25,119]$. Surprisingly, even aging alone lowers $\mathrm{pHi}$ in rat hippocampus, which suggests that aging can decrease the natural resistance to maintain a normal and healthy acid-base homeostasis in the CNS. Perhaps, this happens because time itself decreases the capacity to adapt to different stresses and energetic demands ("the stress of life" in Hans Selye) [244]. This phenomenon appears to be the mirror image of what Otto Warburg once said regarding the cancer situation, namely, that "only time causes cancer" [245].

\subsection{Inhibition of ion on channels in neuroprotection and cancer.}

It has already been considered that the myelin-producing oligodendrocytes are a fundamental issue in MS in order to repair the damaged nerves [246]. It has also been noted that a hostile acid-base microenvironment can diminish the remyelination potential of oligodendrocytes [97]. The same authors have shown that an acidic pHe decreases the migration, proliferation and survival of oligodendrocytes. Microenvironmental acidity also appears to be a fundamental metabolic factor in inducing a decreased remyelination, at the same time that hinders axonal regeneration and normal neurological functions [6,7].

From a therapeutic perspective, neural cell death induced by acidosis is inhibited by ASIC1 blockers. ASIC1 contributes to the damaging i.c. accumulation of $\mathrm{H}^{+}, \mathrm{Na}^{+}$and $\mathrm{Ca}^{++}$ and is over-expressed in acute MS lesions [114]. ASIC1 inhibitors, like amiloride and its potent derivative benzamil, are considered to be effective in improving the symptoms of Huntington disease (HD) [13] (section 2.4.2) (Box 2). Thus, the pharmacological targeting of ion channels $[50,109,110]$, such as Nav channels and acid-sensing $\mathrm{Ca}^{++}$-permeable channels, represent a rational strategy that can be exploited as a preventive measure in neuroprotection [20], as well as in the treatment of different HNDDs [50,109]. Importantly, there are some ASCIs inhibitors clinically available nowadays, that can already be used in humans. These are considered in the next section 2.3. Finally, very complete lists of potential neuroprotective agents in MS have been published over the years [247].

\subsection{Clinically available ASIC inhibitors and other measures in the metabolic-derived treatment of $H N D D$ s and MS.}

Axon remyelination in the central nervous system requires oligodendrocytes that produce myelin. Failure of this repair process is characteristic of neurodegeneration in demyelinating diseases such as multiple sclerosis, and it remains unclear how the lesion microenvironment contributes to decreased remyelination potential of oligodendrocytes. Here, we show that acidic extracellular $\mathrm{pH}$, which is characteristic of demyelinating lesions, decreases the migration, proliferation, and survival of oligodendrocyte precursor cells (OPCs), and reduces their differentiation into oligodendrocytes. Further, OPCs exhibit directional migration along $\mathrm{pH}$ gradients toward acidic $\mathrm{pH}$. These findings support a possible scenario whereby $\mathrm{pH}$ gradients attract OPCs toward acidic lesions, but 
resulting reduction in OPC survival and motility in acid decreases progress toward demyelinated axons and is further compounded by decreased differentiation into myelinproducing oligodendrocytes. As these processes are integral to OPC response to nerve demyelination, our results suggest that lesion acidity could contribute to decreased remyelination.

The main therapeutic aim is to find further and even alternative approaches, that can improve the therapeutic results in the treatment of HNDDs, and more specially of MS. This is because MS, as a neurodegenerative process represents a case apart among HNDDs. Thus, it deserves an special study, either because its paradoxical saw tooth evolution, its metabolic-and lactate specific abnormalities and its selective immune implications. To a certain extent, these special features separate MS from other HNDDs. No matter what, in any of these neurological degenerations, certain drugs are aimed to rescuing the acidotoxicity induced by ASIC1, either by downregulating or by blocking it. Besides, it is most important to realize that. Among the ASCI inhibitors that are clinically available nowadays, amiloride, as well as its more potent and specific derivative benzamil, have been shown to be effective at least in improving some of the molecular characteristics of an HNDD like HD [13]. In the same line, benzamil and dichlorobenzamil, as well as bepridil, also exhibit neuroprotective properties in an optic nerve model. Further, bepridil has been reported to protect myelinated axons from degeneration [121] (see sections 2.4.2. and 2.4.3., and Box 2).

2.4. Amiloride (AM) and amiloride derivatives in the neurology and oncology clinics. Benzamil, bepedril, cariporide and other proton transport inhibitors (Box 2).

2.4.1. Amiloride (AM) has been shown to have protective effects in different neurodegenerative situations.

It preserves myelin even in hypoxic and inflammatory conditions [112]. This suggests that NHE1 inhibition with AM can offer a means of treating necrosis and apoptosis in neurodegeneration also as a preventive measure. Blocking NHE1 activation with more specific and powerful NHE inhibitors, however not yet clinically available, like cariporide, might provide a stronger neuroprotection by protecting cells, not only from pathological increases in cellular $\mathrm{Ca}^{++}$entry, but also by downregulating the production, and decreasing the cellular overload of reactive oxygen species (ROS) [122]. Furthermore, inhibiting ASIC1 also decreases axonal injury and demyelization [117]. Finally, selectively blocking the $\mathrm{Na}^{+} / \mathrm{Ca}^{++}$exchanger (NCX) also results in neuroprotection of the white matter [121].

Furthermore, the neuroprotective effects Amiloride (AM) as a non-specific NHE inhibitor as well as $\mathrm{Na}^{+}, \mathrm{Ca}^{++}$and $\mathrm{K}^{+}$-gated inhibitor, have been tested in patients with primary progressive MS [248]. No matter that this study included a small cohort of patients and extremely low doses of AM (10 mg/day), the authors conclude that AM appears to be useful in neuroprotection in patients with progressive MS. On the contrary, in other large cohort studies AM users with MS were not associated with a decreased incidence of the disease or death [249]. It could be that the use of AM as a channel blocker has been disappointing due to its short duration of action or the low dosages utilized in all these clinical studies.

Mainly in cancer research and treatment, there is a great deal of basic and animal research studies, as well as some clinical experience, on the long term utilization of AM and its more potent derivatives, [111,123-125]. In our hands, AM has been used long term at a dose of $10 \mathrm{mgr}$., three times/daily, with occasionally higher dosages up to $60 \mathrm{mgr} /$ day in divided doses, continuously over months and even years [123,125]. At dosages of 30 $\mathrm{mgr} / \mathrm{day}, \mathrm{AM}$ is very well tolerated. Occasionally, some degree of hyperkaliemia ensues $\left(\mathrm{K}^{+}\right.$up to $6 \mathrm{mmol} / \mathrm{L}$ ) and/or increases in BUN (up to $90 \mathrm{mg} / \mathrm{dL}$ ). Then, AM is discontinued for two weeks and restarted at a lower dose [124-126]. There are other more powerful and specific NHE and ASIC1 inhibitors that have to be taken into account, however some of the most promising ones have not yet reached the clinical stage of research [10]. 


\subsubsection{Benzamil.}

Benzamil is an AM analogue with a longer duration of action than AM. Via nasal spray, it has been used for the treatment of patients with cystic fibrosis as a $\mathrm{Na}^{+}$channel blocker $[128,250]$. Benzamil has also been used as a voltage-gated $\mathrm{K}^{+}$channel blocker for the treatment of psoriasis and used as topical cutaneous administration [129]. However, in spite that benzamil is on the market, to date it has not been tried in MS or any other HNDDs. It could be utilized as a repurposed drug and as a non-label drugin MS.

\subsubsection{Bepedril.}

Bepedril is a voltage-gated $\mathrm{Ca}^{++}$channel blocker thathas been used to treat atrial fibrillation. While it was shown to have in vitro activity against MS is no longer on the market since it was blamed to induce ventricular arrhythmias [251,252]. Bepridil and benzamil, through their effects as inhibitors of either the $\mathrm{Na}^{+} / \mathrm{Ca}^{++}$exchanger (NCX) or NHE, or both, are also effective in inhibiting the growth of brain tumor cells in vitro by increasing intracellular $\mathrm{Ca}^{++}$to toxic levels, so facilitating apoptosis [251].

\subsubsection{Cariporide (CP).}

$\mathrm{CP}$ has been mainly used in cardioprotection in large cardiology trials [111]. However, while this drug is easily available in a highly purified form from different chemical and pharmacological sources around the world, it is most unfortunate that has never been tested, either in clinical or preclinical oncology or neurology. Recent studies in an in vitro model of excitotoxic neuronal death reported that $\mathrm{CP}$, perhaps paradoxically at first sight, protected neurons from ischemic injury, an effect ascribed to the prevention of CNS apoptosis. In that study, CP $(100 \mathrm{nM})$ attenuated glutamate-mediated mitochondrial death pathways involving loss of mitochondrial membrane potential, as well as $\mathrm{Ca}^{++}$and $\mathrm{ROS}$ accumulation [130]. These results further show that NHE1 inhibition offers a means of preventing both necrosis and apoptosis in HNDDs.

\subsection{Other anti-MS drugs: Aminopyridine and nafamostat mesylate.}

\subsubsection{Aminopyridine (4-AP).}

This drug shows some effectiveness in the control of symptoms and on the course of MS [131]. 4-AP works as a potassium $\mathrm{K}^{+}$channel blocker and it is clinically approved to treat walking deficiencies in patients with MS. It helps to improve nerve conduction induced by demyelination [132]. It is commercialized under the trade name of Ampyra (dalfampridine) and is available as $10 \mathrm{mg}$ tablets. However, 4 -AP is not free of potentially serious side-effects.

\subsubsection{Nafamostat. mesylate (NM).}

NM is a serine-protease and ASCI1 inhibitor and is clinically available. It is used as an anticoagulant and also to treat pancreatitis and osteoarthritis [128]. In combination with other therapies, NM has also been tried in Phase I and II in cancer patients [133]. As far as we are aware of, it has not yet been utilized in the prevention or treatment of MS or other HNDDs.

\subsection{Growth factors ( $h G F s$ ) and platelet-derived growth factors (PRGF) in MS and HNDDs.}

A wide array of human growth factors (hGFs) have been tried for neuronal protection in HNDDs, either induced by human growth hormone (hGH) $[137,138]$ or derived from platelet concentrates (PRGF) (see Figure 1 in ref. [139]. In this line, intranasal delivery of PRGF has been shown to stimulate neurogenesis and decrease neurodegeneration in mice models of $\mathrm{AD}$, also improving cognitive functions [139]. These authors have also shown that PRGF preparations induce neuroprotection in rodent models of Parkinson's disease (PD) [140]. However, in spite that some relationships between PRGF, NO 
production and acid-base changes in HNDDs have been described, their interrelationships are not fully understood [6,30,31]. To date, it is not known if these experimental results mediated by PRGF and/or hGH are secondary to their effect in maintaining cellular acid-base homeostasis within a physiological range or to a different mechanism $[6,8,118]$.

\subsection{Growth hormone ( $h G H)$ in MS and HNDDs and their implications in treatment.}

Ageing is related to the progressive decrease of the production of several neurotrophic factors, hGH among them [253]. In rats, GH administration induces neural cell proliferation [142,254]. Also in rats, GH promotes motor function after frontal cortex lesions. Importantly, hGH induces the expression of a number of neurotrophic factors (IGFI, EGF and its receptor, EPO, VEGF, NGF), also increasing turnover of NA (Noradrenaline) and DA (Dopamine) in the brain [145-149,253]. In mice models of ALS, GH plays a protective effect on motor neurons, increasing survival times and improving motor performance [150]. Besides, the peripheral administration of GH in models of AD in rats improves spatial cognition, as well as learning and memory [151]. These results suggest the possible usefulness of hGH in AD in humans, also in combination with other measures [152]. While hGH concentrations are low in the CSF of patients with ALS, when used alone its administration has effect on the clinical progression of this fatal HNDD [153].

GH plays a very important role in the development and maintenance of brain functions [149]. In fact, the brain has been considered to be a GH-target tissue [255]. Moreover, there is a production of $\mathrm{GH}$ and its receptor in neural stem cells, where the hormone induces their proliferation and differentiation [254]. This cerebral GH may cooperate with pituitary GH or that exogenously administered GH to increase its effect on neurogenesis. These effects have been observed in rats [254].

In humans, hGH administration has been reported to improve cognition and other neuronal alterations induced by cerebral palsy, or traumatic brain injury, or old age, like learning and memory [141,148,154,157].

Moreover, GH administration is able to recover mild cognitive deficit in an elder patient with ApoE 4/3 Genotype [256] in agreement with the results above described in a model of AD in rats [150].

Otherwise, GH has been shown to recover the sciatic nerve after its transection in rats, inducing the formation of a high number of myelinating Schwann cells [143]. Even more, GH treatment has been able to fully promote distal innervation in a case of Caudal Regression Syndrome [155].This also indicates that GH is able to induce myelination or remyelination, therefore suggesting its usefulness in the treatment of MS. Moreover, GH induces IGF-I expression and this peptide has been shown to promote proliferation of OPC and differentiation and survival of oligodendrocytes [156,257], an effect also induced by EGF [258] whose expression, as well as that of its receptor may also be induced by GH.

Altogether, these data suggest that GH administration could be useful in the treatment of MS and, in fact, both published data [259] and preliminary data from our group show a therapeutic response in some patients, but only when the disease is not active, most likely because the role of GH in remyelination cannot occur when the oligodendrocyte microenvironment is acidic. On the other hand, a deficient secretion of GH does not seem to play any role in the development of the disease, although lower plasma GH levels have been found in patients with more severe disease [259].

\subsection{Melatonin (MT) in MS, HNDDs and cancer therapeutics.}

\subsubsection{Melatonin (MT) in MS and HNDDs.}

Cell death and survival are the two most critical events in neurodegeneration [6], with mitochondria being increasingly seen as an important determinant of both processes [214,260,261]. MT can prevent the NO stress-induced mitochondrial dysfunction in experimental models of AD, PD and HD [158]. MT is a scavenger of hydroxyl, carbonate, alkoxyl, peroxyl and aryl cation radicals, while stimulates antioxidative enzymes like 
glutathione peroxidase and superoxide dismutase (SOD), besides suppressing NO synthase [262]. Moreover, MT inactivates the ROS-dependent Akt signaling pathway and downregulates signals involved in pro-oxidant pathways. MT production is decreased in neurodegenerative diseases. In the case of MS some studies showed that plasma and urine levels of MT are lower in these patients than in healthy age-matched controls and that the circadian rhythm of pineal MT secretion is disrupted and more affected as the severity of the disease increases, therefore the extra-pineal mitochondrial production of MT has also to be affected [263].

As a consequence of the oxidative stress initially produced by gut dysbiosis and given the antioxidant properties of MT and its properties as an inhibitor of neuroinflammation, mitochondrial protector, anti-apoptotic and anti-autophagic effects, treatment with this hormone has to be taken into account in the treatment of HNDDs [264]. The antiinflammatory effects of MT take place by decreasing plasma levels of proinflammatory cytokines, while its anti-apoptotic effects depend on upregulating Bcl-2 expression and decreasing caspase-3 and Bax levels [265].

Many studies have considered the potential role of MT in HNDDs like MS, AD, PD and ALS. In mouse models of $\mathrm{AD}$, a significant clinical improvement with chronic MT treatment at daily dosages of $10 \mathrm{mgr} / \mathrm{kg} / \mathrm{day}$ was found [266]. Also, an improvement of cognition and memory as well as a reduction of the deposits of $A \beta$ has been reported [159]. Importantly too, MT also appears to be most beneficial in other neurovascular diseases like Horton's disease ("cluster headaches") when used in high doses, ranging from 50 to $350 \mathrm{mgr} /$ day $[267,268]$.

In an animal model of sporadic AD in rats, MT decreases the levels of amyloid- $\beta 1-$ 42 , amyloid- $\beta 1-40$ and amyloid- $\beta 1-42$ [160]. These properties also make MT an important therapeutic weapon in order to protect the entire organism against oxidative stress $[158,161]$. In summary, MT administration at pharmacological dosages should be considered in the adjuvant treatment of certain HNDDs like MS [163,264]. We use 50-400 mg/day of MT, orally. It is concluded that the use of MT should be seriously considered in the adjuvant treatment of certain HNDDs like MS.

\subsubsection{Melatonin in cancer.}

In the cancer context, many studies have shown the important actions that MT play in the treatment of malignancy, either on its own or as an adjuvant of chemo-radiotherapy [269-273].

In addition to its known anti-cancer effects as antioxidant, MT may act on tumors epigenetically, thus increasing its therapeutic possibilities [274].

Finally, the therapeutic spectrum of MT in cancer is broadened by its protective actions against the development of mucositis or dermatitis during chemotherapy or radiotherapy treatments [275-277].

\subsection{Treating microbiota in neurodegeneration.}

Gut microbiota has been associated in a cause-effect relationship with diseases of the CNS, mainly with MS. The analyisis of microbiota in HNNDs reveals a decrease in shortchain fatty acids (SCFAs). Butyrate is a short chain fatty acid synthesized by gut microbiota. It shows promising activities in other many metabolic disorders, like insulin resistance, hypercholesterolemia and many genetic metabolic diseases [278]. Treatment with butyrate in tissue culture preparations increases oligodendrocyte differentiation and remyelination [136]. Further, $\alpha$-linolenic acid (ALA) and valproic acid (VPA) conjugates counteract neurodegeneration and demyelination, also inducing oligodendrocyte precursor cell differentiation in MS [279]. Importantly, microbial colonization of intestine begins shortly after birth, and it has become clear that an abnormal composition of the microbiota means a clear risk of developing HNDDs, and also some types of cancer. So, the goal should be to achieve a normal intestinal flora. Probably everyone, starting at a certain age, 
should perform a stool analysis to assess the composition of his/her microbiota and the relative abundance of harmful bacteria in it, in order to take the appropriate measures for its correction. But apart from this, it seems clear that eating an adequate diet, avoiding alcohol consumption and smoking, consuming vegetable fiber, having an adequate supply of vitamins (A and D, above all), avoiding stress and carrying out regular physical activity will help our intestinal flora to have the proper composition.

In gut dysbiosis some additional measures can be taken. Although antibiotics usually alter the normal composition of gut microbiota, in an experimental model of MS has been shown that the oral (but not intraperitoneal) administration of a specific cocktail of antibiotics (vancomycin, ampicillin, neomycin sulfate, and metronidazole) for seven days, significantly reduces the severity of Experimental Autoimmune Encephalomyelitis (EAE), a well-established model of MS in mice, which is induced by proteolipid protein or myelin oligodendrocyte glycoprotein challenge [280]. The mechanisms by which this cocktail acts and protects from EAE suggests an induction of protective Treg cells and a reduction in the intestinal bacterial load. These led to decreased inflammatory responses. More recently, it has been demonstrated that Farnesol, an organic isoprenol produced in plants and mammals, who has potent anti-oxidant, anti-inflammatory and neuroprotective activities, can protect against central and spinal demyelination by changing the gut microbiota composition, specifically decreasing the Firmicutes/Bacteroidetes ratio [281].

Although it has not been proved that MT could be able to correct gut dysbiosis, another recent study demonstrates that oral MT is able to reduce the production of Lipopolysaccharide (LPS) by intestinal Escherichia coli, therefore improving intestinal and adipose lipid dysmetabolism [162]. Since LPS plays an important role in the development of MS, it would be interesting to study whether MT is able to regulate gut dysbiosis.

Also in recent years, it has been proposed that gut dysbiosis could be treated by means of a fecal microbiota transplant (FMT) from a healthy donor. This FMT can be carried out by means of a oral capsule containing stool or by direct colonoscopy. Advantages of FMT for correcting gut dysbiosis are many, mainly if this transplant is performed occasionally. However, there is the need of a wide analysis of the sample to be transplanted, since the possibility exists, as it has happened, that this material could contain dangerous toxins proceeding from unidentified pernicious bacteria hosted in the donor. A detailed explanation of this procedure as well as of its possible problems and future prospects can be seen in the recent review carried out by Ser et al [282].

\subsection{Butyrate, Propionate, Vitamin A and Vitamin D in MS and HNDDs.}

As stated before, a normal intestinal production of Butyrate and Propionate protects the intestinal barrier avoiding the entry of harmful metabolites and toxins into the host. Moreover, at the intestinal level these SFACs regulate the immune response increasing Treg cells population. Therefore, gut dysbiosis leading to the loss of production of these SCFAs facilitates the development of HNDDs. In the case of MS, the disease is triggered by peripherally stimulated autoreactive lymphocytes that cross the BBB and change to be myelin antigens in the CNS [134]. SCFAs administration, mainly propionate, increases Treg cells population and changes $\mathrm{T}$ cell differentiation to anti-inflammatory Treg cells and reduces pro-inflammatory T-lymphocytes [135]. Moreover, it has been demonstrated that the oral administration of SCFAs recovers demyelination induced by cuprizone and facilitates the differentiation of oligodendrocytes [136].

Consequently, it is likely that the oral administration of SCFAs may be useful for the treatment and recovery of a disease like MS that, until now, has not achieved significant improvements with the therapies currently used. Even more, oral SCFAs can be given together with any of the current treatments for this disease. In our group, after fully analyzing the composition of the stool we use MT and sodium butyrate ( 1 gr/day) or sodium propionate ( $1 \mathrm{gr} /$ day). Even though the disease is not fully stopped, the interval between relapses increases and allows remyelination by administering $\mathrm{GH}$. 
Another alternative, not incompatible with what has been already described, is the oral administration of vitamin $\mathrm{A}$ in the diet, preferably as beta-carotenes, given its intestinal metabolization towards retinoic acid, and vitamin D (4.000 IU/day), given its immunomodulatory properties. Finally, sodium butyrate can also be useful as an adjuvant treatment in some cancers, given its antioxidant and epigenetics properties [274].

\subsection{Nitric oxide (NO) inhibitors in MS.}

Although nitric oxide (NO) is a vasodilator, so promoting oxygenation [164], under certain circumstances, NO and its derivative peroxynitrite (ONOO-), support MS pathogenicity through the activation of inducible nitric oxide synthase (iNOS) which is increased in MS patients [164,165]. One of the mechanisms describing how NO is associated with MS is that NO depletes the cells of cellular antioxidants agents, inhibiting the mitochondrial respiratory chain and altering other cellular metabolic pathways [166-172]. Agmatine is a NO inhibitor [283] that shows activity against MS in vivo when it is administered at a dose $100 \mathrm{mg} / \mathrm{kg} / \mathrm{day}$. Thus, this drug should be also considered in the complementary treatment of MS [173].

\subsection{Hydralazine in MS.}

Hydralazine works as a vasodilator, so promoting oxygenation and decreasing the accumulation of LA. It has shown promising effects in the management of MS [174,175].

2.13. Mitochondrial booster agents in MS: methylene blue, alpha lipoic acid, and fermented wheat germ extract.

Some mitochondrial booster agents include methylene blue, alpha-lipoic acid, and fermented wheat germ extract $[176,177,284,285]$.

\subsubsection{Methylene blue (MB).}

$\mathrm{MB}$ is a mitochondrial function restorative agent [177] that has a pharmacological role in the management of MS [176]. Interestingly, MB also suppresses nitric oxide (NO) production. However, some data has sown a lack of activity of MB against MS [178].

\subsubsection{Alpha lipoic acid ( $\alpha$-LA).}

$\alpha$-LA is a mito-booster agent that is widely used to manage diabetic neuropathy when administered intravenously at a dose of $600 \mathrm{mg} /$ day over a period of 3 weeks [286,287].

\subsubsection{Fermented Wheat Germ Extract (FWGE, Metatrol®).}

Metatrol is a potent mito-booster agent [179] that has been widely used as anti-aging as well as an anti-cancer drug in many human malignancies $[179,288,289]$. These authors have reported that FWGE suppresses the Warburg effect, restores oxidative mitochondrial activity and increases of the carbon flux into the mitochondria. It has also been reported to inhibit in vivo tumor growth and used in a clinical oncological context [179]. Besides, FWGE inhibits metastatic tumor dissemination and proliferation during and after chemotherapy, surgery or radiation in cancer patients, also being beneficial in autoimmune diseases [290]. For all these reasons, FWGE has become a promising factor in the therapeutics of MS in an attempt to decrease LA burden as well as to control systemic symptoms of the disease. The daily recommended dose of FWGE is 2 capsules/day (395 $\mathrm{mg}$ each) for people under $200 \mathrm{lb}$, and 4 capsules/day for those who weigh $200 \mathrm{lb}$ or more [180].

\subsection{Calcium $\left(\mathrm{Ca}^{++}\right)$entry inhibitors in $\mathrm{MS}$.}

Calcium homeostasis is a fundamental process in cellular physiology. However, increasing i.c. calcium leads to stimulation of a cascade of biochemical reactions that end up in the formation of ROS, which stimulates apoptosis. Also, increasing calcium entry might 
associated with increasing excitatory changes in certain neurotransmitters, e.g., glutamate, which is associated with Tumor Necrosis Factor-alpha (TNF- $\alpha$ ). This association can also be interlinked with Transient Receptor Potential Melastatin 2 (TRPM2) that stimulates calcium entry and neuroinflammation [181-184]. Thus, increasing calcium entry leads to the development of MS [185-187]. Administration of agents that interfere with calcium entry represents a potential neuroprotective strategy in MS development (e.g., Olesoxime, Quetiapine, Glutathione, Nimodipine and vitamin D) [188,189]. Daily dosages of vitamin D in these cases range from 2000 and 5000 IU [291,292]. Finally, Bepridil also works as a $\mathrm{Ca}^{++}$channel blocker and has shown a dramatic effect in managing MS in model systems (the dosage in mice being $3 \mathrm{mg} / \mathrm{kg}$, subcutaneously) [190].

\subsection{Caspase-3 inhibitors in MS.}

The caspase- 3 protein belongs to the cysteine-aspartic acid protease (caspase) family [293-295]. Caspase-3 promotes pyroptosis (apoptosis-associated with a high inflammatory component) [191,192]. Therefore, suppressing pyroptosis becomes a promising strategy in the management of MS [192,193]. N-acetyl-Asp-Glu-Val-Asp-7-amino-4-methyl coumarin (Ac-DEVD-amc) is an example of Caspase-3-inhibitor [296]. This compound significantly supports neuronal survival, at least in vitro [296].

\subsection{Antilactacemics in MS.}

Antihyperlactacemics have been proposed to provide a new therapeutic approach to minimizing myelin degeneration in MS and in other CNS disorders characterized by inflammatory demyelination [15,194]. Hydralazine also decreases the accumulation of LA. In rodents, very positive effects in the management of MS have been shown when administered at a dosage of $1 \mathrm{mg} / \mathrm{kg}[174,175,297]$.

Most importantly, alkaline preparations appear to be a fundamental measure within the treatment of MS. At least they have been shown to relieve MS patients from ocular symptoms, tiredness and muscle pain [298].

A mixture of sodium bicarbonate (SB) and dimethyl sulfoxide (DMSO) has been proved to be a safe and effective treatment of pain in malignancy, probably by decreasing the extracellular acidic pH of tumors [4]. This mixture that also has been clinically used as a harmless antiacid and antilactacemic measure [299-302]. The utilization of DMSO in humans has demonstrated its lack of toxicity when used for periods of up to 5 years. No increases in $\mathrm{Na}^{+}$levels, salt retention or blood pressure changes have been observed Still, $\mathrm{Na}^{+}, \mathrm{K}^{+}$and BUN should be checked at least monthly during this treatment. Recently, the use of DMSO, given orally, topically or intravenously, has also been used in treating autoimmune and ocular diseases [303]. Therefore, it is important to know how DMSO is formulated and used:

\section{Clinical formulation and dosages of the SB+DMSO mixture}

Thirty-four percent DMSO (99.9\% pharmaceutical quality/99.9\% purity), $64 \%$ double-distilled water and $\%$ SB. Dosage: $10-30 \mathrm{mls}$. orally, twice a day, on an empty stomach and separated from other medications. Only crystal bottles or high-density polyethylene (HDPE) should be used as containers, since DMSO can dissolve other kinds of plastic containers and become toxic to the patient.

\section{Conclusions}

This wide-ranged approach to homeostasis, allostasis and their deregulation, allows us to transform a general and non-specific factor, such as the $\mathrm{pH}$ of cells and their microenvironment, into the most specific etiopathogenic parameter in both cancer and HNDDs. This original "both sides now" perspective represents a radical change in other modern approaches to health and disease, departing from some more reductionistic concepts regarding the etiopathogenesis and therapeutics of different diseases and degenerative 
processes. Such an all-embracing perspective, points towards a unified theory of the dualistic apoptosis-antiapoptosis machineries and the pro-death and anti-death mechanisms in cellular deregulation. This paradigm hierarchically integrattes under a Unitarian viewpoint different levels of understanding, from basic to clinical research, from molecular biology to biochemistry and metabolism and from etiopathogenesis to treatment.

As the result of this new theoretical approach, we have considered the integrated utilization of wide array of therapeutic measures in MS and HNDDs, as we have previously done in the field of cancer. The final aim of these efforts are: a) improving the treatment of HNNDs, specially MS, in order to prevent, and if possible, reverse, the acidification-dependent neural toxicity and progressive apoptosis characteristic of neurodegeneration, and b) stimulate cellular metabolism in order to recover cell and microenvironmental homeostasis and so prevent and treat the metabolic collapse and cellular death taking place in MS and HNDDs.

Interestingly, and although this may appear as a paradox at first sight, in spite that cancer and HNDDs present themselves at all levels of study as opposite processes when based upon their cellular $\mathrm{pH}$-deviations and their respective hydrogen dynamics, some of the medications advised for HNDDs are also are indicated in cancer treatment.

Author Contributions: Conceptualization, S.H., KA and JD; methodology, S.H., K.A. and J.D.; validation, S.H., and J.D.; formal analysis, S.H, S.R., and J.D.; investigation, S.H., K.A., and J.D.; writing - original draft preparation, S.H.; writing - review and editing, S.H., K.A., S.R., and J.D.; funding acquisition., J.P.O. All authors have read and agreed with the published version of the manuscript.

Funding: This research was funded by The Mercedes Castresana Foundation (Vitoria, Spain), and the Association for Proton Cancer Research and Treatment (APCRT), Madrid, Spain.

Acknowledgments: We wish to apologize to all of the authors in the field whose publications have not be included in this contribution.

Conflicts of Interest: The authors declare no conflict of interest. The funder had no role in the design of the study or in the collection, analyses and interpretation of data; neither in the writing of the manuscript or in the decision to publish the results. Declaration of interests: none.

\section{References}

[1] Harguindey: S.; Katin, M.; Edgerton, F.; Takita, H., Hierarchical organization, integrations in biology and cancer, balance loss, and a question on modernism. Med. Hypotheses 1981, 7, 1123-1132. [http://doi.org/10.1016/0306-9877(81)90054-2].

[2] Cannon, W.B., Organization for physiological homeostasis. Physiol. Rev. 1929, 9, 399-431. [http://doi.org/doi.org/10.1152/physrev.1929.9.3.399].

[3] Selye, H., The evolution of the stress concept. Am. Sci. 1973, 61, 692-699. [http://doi.org/4746051].

[4] Harguindey, S.; Stanciu, D.; Devesa, J.; Alfarouk, K.; Cardone, R.A.; Polo Orozco, J.D.; Devesa, P.; Rauch, C.; Orive, G.; Anitua, E., et al., Cellular acidification as a new approach to cancer treatment and to the understanding and therapeutics of neurodegenerative diseases. Semin. Cancer Biol. 2017, 43, 157-179. [http://doi.org/10.1016/j.semcancer.2017.02.003].

[5] Harguindey, S.; Reshkin, S.J., "The new pH-centric anticancer paradigm in Oncology and Medicine"; SCB, 2017. Semin. Cancer Biol. 2017, 43, 1-4. [http://doi.org/10.1016/j.semcancer.2017.02.008].

[6] Harguindey, S.; Orive, G.; Cacabelos, R.; Hevia, E.M.; de Otazu, R.D.; Arranz, J.L.; Anitua, E., An integral approach to the etiopathogenesis of human neurodegenerative diseases (HNDDs) and cancer. Possible therapeutic consequences within the frame of the trophic factor withdrawal syndrome (TFWS). Neuropsychiatr. Dis. Treat. 2008, 4, 1073-1084. [http://doi.org/10.2147/ndt.s3800].

[7] Harguindey, S.; Reshkin, S.J.; Orive, G.; Arranz, J.L.; Anitua, E., Growth and trophic factors, $\mathrm{pH}$ and the $\mathrm{Na}+/ \mathrm{H}+\mathrm{exchanger}$ in Alzheimer's disease, other neurodegenerative diseases and cancer: new therapeutic possibilities and potential dangers. Curr Alzheimer Res 2007, 4, 53-65. [http://doi.org/10.2174/156720507779939841].

[8] Fang, B.; Wang, D.; Huang, M.; Yu, G.; Li, H., Hypothesis on the relationship between the change in intracellular $\mathrm{pH}$ and incidence of sporadic Alzheimer's disease or vascular dementia. Int. J. Neurosci. 2010, 120, 591-595. [http://doi.org/10.3109/00207454.2010.505353].

[9] Schwartz, L.; Peres, S.; Jolicoeur, M.; da Veiga Moreira, J., Cancer and Alzheimer's disease: intracellular pH scales the metabolic disorders. Biogerontology 2020, 1-12. [http://doi.org/10.1007/s10522-020-09888-6.]. 
[10] Xiong, Z.-G.; Pignataro, G.; Li, M.; Chang, S.-y.; Simon, R.P., Acid-sensing ion channels (ASICs) as pharmacological targets for neurodegenerative diseases. Curr. Opin. Pharmacol. 2008, 8, 25-32. [http://doi.org/10.1016/j.coph.2007.09.001.].

[11] Obara, M.; Szeliga, M.; Albrecht, J., Regulation of $\mathrm{pH}$ in the mammalian central nervous system under normal and pathological conditions: facts and hypotheses. Neurochem. Int. 2008, 52, 905-919. [http://doi.org/10.1016/j.neuint.2007.10.015].

[12] Ibarreta, D.; Urcelay, E.; Parrilla, R.; Ayuso, M.S., Distinct pH homeostatic features in lymphoblasts from Alzheimer's disease patients. Ann. Neurol. 1998, 44, 216-222. [http://doi.org/10.1002/ana.410440212].

[13] Wong, H.K.; Bauer, P.O.; Kurosawa, M.; Goswami, A.; Washizu, C.; Machida, Y.; Tosaki, A.; Yamada, M.; Knopfel, T.; Nakamura, T., et al., Blocking acid-sensing ion channel 1 alleviates Huntington's disease pathology via an ubiquitin-proteasome systemdependent mechanism. Hum. Mol. Genet. 2008, 17, 3223-3235. [http://doi.org/10.1093/hmg/ddn218].

[14] Chaumeil, M.M.; Valette, J.; Baligand, C.; Brouillet, E.; Hantraye, P.; Bloch, G.; Gaura, V.; Rialland, A.; Krystkowiak, P.; Verny, C., $\mathrm{pH}$ as a biomarker of neurodegeneration in Huntington's disease: a translational rodent-human MRS study. J. Cereb. Blood Flow Metab. 2012, 32, 771-779. [http://doi.org/10.1038/jcbfm.2012.15].

[15] Young, P.R.; Snyder, W.R.; Vacante, D.A.; Waickus, C.M.; Zygas, A.P.; Grynspan, F.; Karunatilake, C.; Wilson, D.H., The acid instability of myelin. A model for myelin degeneration in multiple sclerosis. Med. Hypotheses 1988, $26,31-37$. [http://doi.org/10.1016/0306-9877(88)90110-7].

[16] Atwood, C.S.; Moir, R.D.; Huang, X.; Scarpa, R.C.; Bacarra, N.M.; Romano, D.M.; Hartshorn, M.A.; Tanzi, R.E.; Bush, A.I., Dramatic aggregation of Alzheimer abeta by $\mathrm{Cu}(\mathrm{II})$ is induced by conditions representing physiological acidosis. J. Biol. Chem. 1998, 273, 12817-12826. [http://doi.org/10.1074/jbc.273.21.12817].

[17] Nottingham, S.; Leiter, J.C.; Wages, P.; Buhay, S.; Erlichman, J.S., Developmental changes in intracellular pH regulation in medullary neurons of the rat. Am. J. Physiol. Regul. Integr. Comp. Physiol. 2001, 281, R1940-1951. [http://doi.org/10.1152/ajpregu.2001.281.6.R1940].

[18] Deitmer, J.W.; Rose, C.R., pH regulation and proton signalling by glial cells. Prog. Neurobiol. 1996, 48, 73-103. [http://doi.org/10.1016/0301-0082(95)00039-9].

[19] Nedergaard, M.; Goldman, S.A.; Desai, S.; Pulsinelli, W.A., Acid-induced death in neurons and glia. J. Neurosci. 1991, 11, 24892497. [http://doi.org/10.1523/INEUROSCI.11-08-02489.1991.].

[20] de Ceglia, R.; Chaabane, L.; Biffi, E.; Bergamaschi, A.; Ferrigno, G.; Amadio, S.; Del Carro, U.; Mazzocchi, N.; Comi, G.; Bianchi, V., et al., Down-sizing of neuronal network activity and density of presynaptic terminals by pathological acidosis are efficiently prevented by Diminazene Aceturate. Brain. Behav. Immun. 2015, 45, 263-276. [http://doi.org/10.1016/j.bbi.2014.12.003].

[21] Kuo, S.W.; Jiang, M.; Heckman, C., Potential involvement of intracellular $\mathrm{pH}$ in a mouse model of amyotrophic lateral sclerosis. Amyotroph Lateral Scler Frontotemporal Degener 2014, 15, 151-153. [http://doi.org/10.3109/21678421.2013.850096].

[22] Urbano, F.J.; Lino, N.G.; Gonzalez-Inchauspe, C.M.; Gonzalez, L.E.; Colettis, N.; Vattino, L.G.; Wunsch, A.M.; Wemmie, J.A.; Uchitel, O.D., Acid-sensing ion channels 1a (ASIC1a) inhibit neuromuscular transmission in female mice. Am. J. Physiol. Cell Physiol. 2014, 306, C396-406. [http://doi.org/10.1152/ajpcell.00301.2013].

[23] Burtscher, J.; Millet, G.P., Hypoxia, Acidification and Inflammation: Partners in Crime in Parkinson's Disease Pathogenesis? Immuno 2021, 1, 78-90. [http://doi.org/doi.org/10.3390/immuno1020006].

[24] Taylor, C.P.; Meldrum, B.S., Na+ channels as targets for neuroprotective drugs. Trends Pharmacol. Sci. 1995, 16, 309-316. [http://doi.org/10.1016/s0165-6147(00)89060-4].

[25] Ruffin, V.A.; Salameh, A.I.; Boron, W.F.; Parker, M.D., Intracellular pH regulation by acid-base transporters in mammalian neurons. Front. Physiol. 2014, 5, 43. [http://doi.org/10.3389/fphys.2014.00043].

[26] Anitua, E.; Pascual, C.; Antequera, D.; Bolos, M.; Padilla, S.; Orive, G.; Carro, E., Plasma rich in growth factors (PRGF-Endoret) reduces neuropathologic hallmarks and improves cognitive functions in an Alzheimer's disease mouse model. Neurobiol. Aging 2014, 35, 1582-1595. [http://doi.org/10.1016/j.neurobiolaging.2014.01.009].

[27] Torres-Lopez, J.E.; Guzman-Priego, C.G.; Rocha-Gonzalez, H.I.; Granados-Soto, V., Role of NHE1 in Nociception. Pain Res Treat 2013, 2013, 217864. [http://doi.org/10.1155/2013/217864].

[28] Zhang, J.; Peng, H.; Veasey, S.C.; Ma, J.; Wang, G.F.; Wang, K.W., Blockade of Na+/H+ exchanger type 3 causes intracellular acidification and hyperexcitability via inhibition of $\mathrm{pH}$-sensitive $\mathrm{K}+$ channels in chemosensitive respiratory neurons of the dorsal vagal nucleus in rats. Neurosci. Bull. 2014, 30, 43-52. [http://doi.org/10.1007/s12264-013-1373-4].

[29] Majdi, A.; Mahmoudi, J.; Sadigh-Eteghad, S.; Golzari, S.E.; Sabermarouf, B.; Reyhani-Rad, S., Permissive role of cytosolic pH acidification in neurodegeneration: a closer look at its causes and consequences. J. Neurosci. Res. 2016, 94, 879-887. [http://doi.org/10.1002/jnr.23757].

[30] Vincent, A.M.; TenBroeke, M.; Maiese, K., Neuronal intracellular pH directly mediates nitric oxide-induced programmed cell death. J. Neurobiol. 1999, 40, 171-184. [http://doi.org/10.1002/(sici)1097-4695(199908)40:2<171::aid-neu4>3.0.co;2-f]].

[31] Yuste, J.E.; Tarragon, E.; Campuzano, C.M.; Ros-Bernal, F., Implications of glial nitric oxide in neurodegenerative diseases. Front. Cell. Neurosci. 2015, 9, 322. [http://doi.org/10.3389/fncel.2015.00322].

[32] Harguindey, S.; Alfarouk, K.; Polo Orozco, J.; Fais, S.; Devesa, J., Towards an integral therapeutic protocol for Breast Cancer based upon the new $\mathrm{H}+$-centered anticancer paradigm of the late post-Warburg era. Int. J. Mol. Sci. 2020, $21,7475$. [http://doi.org/10.3390/ijms21207475.

[33] Reshkin, S.J.; Bellizzi, A.; Caldeira, S.; Albarani, V.; Malanchi, I.; Poignee, M.; Alunni-Fabbroni, M.; Casavola, V.; Tommasino, $\mathrm{M} ., \mathrm{Na}+\mathrm{H}+$ exchanger-dependent intracellular alkalinization is an early event in malignant transformation and plays an 
essential role in the development of subsequent transformation-associated phenotypes. FASEB J. 2000, 14, $2185-2197$. [http://doi.org/10.1096/fj.00-0029com].

[34] Reshkin, S.J.; Cardone, R.A.; Harguindey, S., Na+-H+ exchanger, pH regulation and cancer. Recent Pat. Anticancer Drug Discov. 2013, 8, 85-99. [http://doi.org/10.2174/157489213803902116].

[35] Reshkin, S.J.; Greco, M.R.; Cardone, R.A., Role of pHi, and proton transporters in oncogene-driven neoplastic transformation. Philos. Trans. R. Soc. Lond. B Biol. Sci. 2014, 369, 20130100. [http://doi.org/10.1098/rstb.2013.0100].

[36] Amith, S.R.; Fong, S.; Baksh, S.; Fliegel, L., Na (+)/H (+)exchange in the tumour microenvironment: does NHE1 drive breast cancer carcinogenesis? Int. J. Dev. Biol. 2015, 59, 367-377. [http://doi.org/10.1387/ijdb.140336lf].

[37] Webb, B.A.; Chimenti, M.; Jacobson, M.P.; Barber, D.L., Dysregulated pH: a perfect storm for cancer progression. Nat. Rev. Cancer 2011, 11, 671-677. [http://doi.org/10.1038/nrc3110].

[38] Gerweck, L.E.; Seetharaman, K., Cellular $\mathrm{pH}$ gradient in tumor versus normal tissue: potential exploitation for the treatment of cancer. Cancer Res. 1996, 56, 1194-1198.

[39] Grillo-Hill, B.K.; Choi, C.; Jimenez-Vidal, M.; Barber, D.L., Increased H(+) efflux is sufficient to induce dysplasia and necessary for viability with oncogene expression. Elife 2015, 4. [http://doi.org/10.7554/eLife.03270].

[40] Harguindey, S.; Alfarouk, K.; Orozco, J.P.; Hardonniere, K.; Stanciu, D.; Fais, S.; Devesa, J., A New and Integral Approach to the Etiopathogenesis and Treatment of Breast Cancer Based upon Its Hydrogen Ion Dynamics. Int. J. Mol. Sci. $2020,21$. [http://doi.org/10.3390/ijms21031110].

[41] Amith, S.R.; Fliegel, L., Regulation of the Na+/H+ Exchanger (NHE1) in Breast Cancer Metastasis. Cancer Res. 2013, 73, 1259-1264. [http://doi.org/10.1158/0008-5472.CAN-12-4031].

[42] Amith, S.R.; Wilkinson, J.M.; Fliegel, L., Assessing Na(+)/H(+) exchange and cell effector functionality in metastatic breast cancer. Biochim Open 2016, 2, 16-23. [http://doi.org/10.1016/j.biopen.2016.01.001].

[43] Lobo, R.C.; Hubbard, N.E.; Damonte, P.; Mori, H.; Penzvalto, Z.; Pham, C.; Koehne, A.L.; Go, A.C.; Anderson, S.E.; Cala, P.M., et al., Glucose Uptake and Intracellular $\mathrm{pH}$ in a Mouse Model of Ductal Carcinoma In situ (DCIS) Suggests Metabolic Heterogeneity. Front. Cell Dev. Biol. 2016, 4, 93. [http://doi.org/10.3389/fcell.2016.00093].

[44] Koltai, T.; Harguindey, S.; Reshkin, S.J., An innovative approach to understanding and treating cancer: Targeting pH. From etiopathogenesis to new therapeutic avenues. Elsevier Publishers: 2019 (In press).

[45] Chauhan, A.S.; Sahoo, G.C.; Dikhit, M.R.; Das, P., Acid-Sensing Ion Channels Structural Aspects, Pathophysiological Importance and Experimental Mutational Data Available Across Various Species to Target Human ASIC1. Curr. Drug Targets 2019, 20, 111121. [http://doi.org/10.2174/1389450119666180820103316.].

[46] Craner, M.J.; Damarjian, T.G.; Liu, S.; Hains, B.C.; Lo, A.C.; Black, J.A.; Newcombe, J.; Cuzner, M.L.; Waxman, S.G., Sodium channels contribute to microglia/macrophage activation and function in EAE and MS. Glia 2005, 49, $220-229$. [http://doi.org/10.1002/glia.20112].

[47] Schwab, A.; Stock, C., Ion channels and transporters in tumour cell migration and invasion. Philos. Trans. R. Soc. Lond. B Biol. Sci. 2014, 369, 20130102. [http://doi.org/10.1098/rstb.2013.0102].

[48] Litan, A.; Langhans, S.A., Cancer as a channelopathy: ion channels and pumps in tumor development and progression. Front. Cell. Neurosci. 2015, 9, 86. [http://doi.org/10.3389/fncel.2015.00086].

[49] Lang, F.; Stournaras, C., Ion channels in cancer: future perspectives and clinical potential. Philos. Trans. R. Soc. Lond. B Biol. Sci. 2014, 369, 20130108. [http://doi.org/10.1098/rstb.2013.0108].

[50] Besson, P.; Driffort, V.; Bon, E.; Gradek, F.; Chevalier, S.; Roger, S., How do voltage-gated sodium channels enhance migration and invasiveness in cancer cells? Biochim. Biophys. Acta 2015, 1848, 2493-2501. [http://doi.org/10.1016/j.bbamem.2015.04.013].

[51] Roger, S.; Gillet, L.; Le Guennec, J.Y.; Besson, P., Voltage-gated sodium channels and cancer: is excitability their primary role? Front. Pharmacol. 2015, 6, 152. [http://doi.org/10.3389/fphar.2015.00152].

[52] Stock, C.; Ludwig, F.T.; Hanley, P.J.; Schwab, A., Roles of ion transport in control of cell motility. Compr Physiol 2013, 3, 59-119. [http://doi.org/10.1002/cphy.c110056].

[53] Luo, Q.; Wu, T.; Wu, W.; Chen, G.; Luo, X.; Jiang, L.; Tao, H.; Rong, M.; Kang, S.; Deng, M., The Functional Role of Voltage-Gated Sodium Channel Nav1.5 in Metastatic Breast Cancer. Front. Pharmacol. 2020, 11, 1111. [http://doi.org/10.3389/fphar.2020.01111].

[54] Huber, V.; Camisaschi, C.; Berzi, A.; Ferro, S.; Lugini, L.; Triulzi, T.; Tuccitto, A.; Tagliabue, E.; Castelli, C.; Rivoltini, L., Cancer acidity: An ultimate frontier of tumor immune escape and a novel target of immunomodulation. Semin. Cancer Biol. 2017, 43, 74-89. [http://doi.org/10.1016/j.semcancer.2017.03.001].

[55] Lacroix, R.; Rozeman, E.A.; Kreutz, M.; Renner, K.; Blank, C.U., Targeting tumor-associated acidity in cancer immunotherapy. Cancer Immunol. Immunother. 2018, 67, 1331-1348. [http://doi.org/10.1007/s00262-018-2195-z].

[56] Pilon-Thomas, S.; Kodumudi, K.N.; El-Kenawi, A.E.; Russell, S.; Weber, A.M.; Luddy, K.; Damaghi, M.; Wojtkowiak, J.W.; Mule, J.J.; Ibrahim-Hashim, A., et al., Neutralization of Tumor Acidity Improves Antitumor Responses to Immunotherapy. Cancer Res. 2016, 76, 1381-1390. [http://doi.org/10.1158/0008-5472.CAN-15-1743].

[57] Wu, H.; Estrella, V.; Enriquez-Navas, P.; El-Kenawi, A.; Russell, S.; Abrahams, D.; Ibrahim-Hashim, A.; Longo, D.; Reshetnyak, Y.; Luddy, K., Lymph Nodes Inhibit T-cell Effector Functions Locally by Establishing Acidic Niches. bioRxiv 2019, 689604. [http://doi.org/10.1101/689604].

[58] Friese, M.A.; Craner, M.J.; Etzensperger, R.; Vergo, S.; Wemmie, J.A.; Welsh, M.J.; Vincent, A.; Fugger, L., Acid-sensing ion channel-1 contributes to axonal degeneration in autoimmune inflammation of the central nervous system. Nat. Med. 2007, 13, 1483-1489. [http://doi.org/10.1038/nm1668]. 
[59] Tolkovsky, A.M.; Richards, C.D., Na+/H+ exchange is the major mechanism of $\mathrm{pH}$ regulation in cultured sympathetic neurons: measurements in single cell bodies and neurites using a fluorescent $\mathrm{pH}$ indicator. Neuroscience 1987, 22, $1093-1102$. [http://doi.org/10.1016/0306-4522(87)92984-8].

[60] Collins, M.K.; Perkins, G.R.; Rodriguez-Tarduchy, G.; Nieto, M.A.; Lopez-Rivas, A., Growth factors as survival factors: regulation of apoptosis. Bioessays 1994, 16, 133-138. [http://doi.org/10.1002/bies.950160210].

[61] Anitua, E.; Sanchez, M.; Orive, G.; Andia, I., The potential impact of the preparation rich in growth factors (PRGF) in different medical fields. Biomaterials 2007, 28, 4551-4560. [http://doi.org/10.1016/j.biomaterials.2007.06.037].

[62] Paris, S.; Pouyssegur, J., Growth factors activate the $\mathrm{Na}+\mathrm{H}+$ antiporter in quiescent fibroblasts by increasing its affinity for intracellular H+. J. Biol. Chem. 1984, 259, 10989-10994. [http://doi.org/https://doi.org/10.1016/S0021-9258(18)90611-3].

[63] Jenkins, E.C.; Debnath, S.; Gundry, S.; Gundry, S.; Uyar, U.; Fata, J.E., Intracellular pH regulation by Na+/H+ exchanger-1 (NHE1) is required for growth factor-induced mammary branching morphogenesis. Dev. Biol. 2012, 365, 71-81. [http://doi.org/10.1016/j.ydbio.2012.02.010].

[64] Ma, E.; Haddad, G.G., Expression and localization of $\mathrm{Na}+\mathrm{H}+$ exchangers in rat central nervous system. Neuroscience 1997, 79, 591-603. [http://doi.org/10.1016/s0306-4522(96)00674-4].

[65] Johri, A.; Beal, M.F., Mitochondrial dysfunction in neurodegenerative diseases. J. Pharmacol. Exp. Ther. 2012, 342, 619-630. [http://doi.org/10.1124/jpet.112.192138].

[66] Muyderman, H.; Chen, T., Mitochondrial dysfunction in amyotrophic lateral sclerosis-a valid pharmacological target? Br. J. Pharmacol. 2014, 171, 2191-2205.

[67] Soane, L.; Kahraman, S.; Kristian, T.; Fiskum, G., Mechanisms of impaired mitochondrial energy metabolism in acute and chronic neurodegenerative disorders. J. Neurosci. Res. 2007, 85, 3407-3415. [http://doi.org/10.1002/jnr.21498].

[68] Barcelos, I.P.; Troxell, R.M.; Graves, J.S., Mitochondrial Dysfunction and Multiple Sclerosis. Biology (Basel) $2019,8,37$. [http://doi.org/10.3390/biology8020037].

[69] Watkins, T.A.; Emery, B.; Mulinyawe, S.; Barres, B.A., Distinct stages of myelination regulated by gamma-secretase and astrocytes in a rapidly myelinating CNS coculture system. Neuron 2008, 60, 555-569. [http://doi.org/10.1016/j.neuron.2008.09.011].

[70] Schoenfeld, R.; Wong, A.; Silva, J.; Li, M.; Itoh, A.; Horiuchi, M.; Itoh, T.; Pleasure, D.; Cortopassi, G., Oligodendroglial differentiation induces mitochondrial genes and inhibition of mitochondrial function represses oligodendroglial differentiation. Mitochondrion 2010, 10, 143-150. [http://doi.org/10.1016/j.mito.2009.12.141].

[71] Bischoff, S.C.; Barbara, G.; Buurman, W.; Ockhuizen, T.; Schulzke, J.-D.; Serino, M.; Tilg, H.; Watson, A.; Wells, J.M., Intestinal permeability-a new target for disease prevention and therapy. BMC Gastroenterol. 2014, 14, 1-25. [http://doi.org/10.1186/s12876014-0189-7].

[72] Hang, Z.; Lei, T.; Zeng, Z.; Cai, S.; Bi, W.; Du, H., Composition of intestinal flora affects the risk relationship between Alzheimer's disease/Parkinson's disease and cancer. Biomed. Pharmacother. 2022, 145, 112343. [http://doi.org/10.1016/j.biopha.2021.112343.].

[73] Rauch, C.; BA W, E.D.; Miriam, L.; Wahl, H.S., Cell Membranes, Cytosolic pH and Drug Transport in Cancer and MDR: Physics, Biochemistry and Molecular Biology. In "Multiple Drug Resistance". A.Meszaros and G.Balogh (eds), Nova Publishers. Multiple Drug Resistance 2009, 1-24. [http://doi.org/http://irep.ntu.ac.uk/id/eprint/34345].

[74] Park, H.J.; Choi, I.; Leem, K.H., Decreased Brain pH and Pathophysiology in Schizophrenia. Int. J. Mol. Sci. 2021, $22,8358$. [http://doi.org/10.3390/ijms22168358].

[75] Harguindey, S.; Orive, G.; Luis Pedraz, J.; Paradiso, A.; Reshkin, S.J., The role of pH dynamics and the Na+/H+ antiporter in the etiopathogenesis and treatment of cancer. Two faces of the same coin--one single nature. Biochim. Biophys. Acta 2005, 1756, 1-24. [http://doi.org/10.1016/j.bbcan.2005.06.004].

[76] Harguindey, S.; Alfarouk, K.; Polo Orozco, J.; Hardonnière, K.; Stanciu, D.; Fais, S.; Devesa, J., A new and integral approach to the etiopathogenesis and treatment of breast cancer based upon its hydrogen ion dynamics. Int. J. Mol. Sci. 2020, $21,1110$. [http://doi.org/https://doi.org/10.3390/ijms21031110].

[77] Perona, R.; Portillo, F.; Giraldez, F.; Serrano, R., Transformation and pH homeostasis of fibroblasts expressing yeast H(+)-ATPase containing site-directed mutations. Mol. Cell. Biol. 1990, 10, 4110-4115. [http://doi.org/10.1128/mcb.10.8.4110-4115.1990].

[78] Wigerup, C.; Pahlman, S.; Bexell, D., Therapeutic targeting of hypoxia and hypoxia-inducible factors in cancer. Pharmacol. Ther. 2016, 164, 152-169. [http://doi.org/10.1016/j.pharmthera.2016.04.009].

[79] Pinheiro, C.; Longatto-Filho, A.; Pereira, S.M.; Etlinger, D.; Moreira, M.A.; Jube, L.F.; Queiroz, G.S.; Schmitt, F.; Baltazar, F., Monocarboxylate transporters 1 and 4 are associated with CD147 in cervical carcinoma. Dis. Markers 2009, 26, 97-103. [http://doi.org/10.3233/DMA-2009-0596].

[80] Miranda-Gonçalves, V.; Granja, S.; Martinho, O.; Honavar, M.; Pojo, M.; Costa, B.M.; Pires, M.M.; Pinheiro, C.; Cordeiro, M.; Bebiano, G., Hypoxia-mediated upregulation of MCT1 expression supports the glycolytic phenotype of glioblastomas. Oncotarget 2016, 7, 46335-46353. [http://doi.org/10.18632/oncotarget.10114].

[81] Martins, S.F.; Amorim, R.; Viana-Pereira, M.; Pinheiro, C.; Costa, R.F.; Silva, P.; Couto, C.; Alves, S.; Fernandes, S.; Vilaca, S., et al., Significance of glycolytic metabolism-related protein expression in colorectal cancer, lymph node and hepatic metastasis. BMC Cancer 2016, 16, 535. [http://doi.org/10.1186/s12885-016-2566-9].

[82] van Kuijk, S.J.; Yaromina, A.; Houben, R.; Niemans, R.; Lambin, P.; Dubois, L.J., Prognostic Significance of Carbonic Anhydrase IX Expression in Cancer Patients: A Meta-Analysis. Front. Oncol. 2016, 6, 69. [http://doi.org/10.3389/fonc.2016.00069]. 
[83] Ferro, S.; Azevedo-Silva, J.; Casal, M.; Corte-Real, M.; Baltazar, F.; Preto, A., Characterization of acetate transport in colorectal cancer cells and potential therapeutic implications. Oncotarget 2016, 7, 70639-70653. [http://doi.org/10.18632/oncotarget.12156].

[84] Counillon, L.; Bouret, Y.; Marchiq, I.; Pouysségur, J., Na+/H+ antiporter (NHE1) and lactate/H+ symporters (MCTs) in pH homeostasis and cancer metabolism. (BBA) - Mol Cell Res 2016, 1863, 2465-2480. [http://doi.org/10.1016/j.bbamcr.2016.02.018].

[85] Behrens, M.I.; Ponce, D.P.; Roe, C.M.; Salech, F., Common Biological Mechanisms in Alzheimer's Disease and Cancer. 2014. In: Advances in Alzheimer's Research vol.2, 2014, 33-57. (Ed). D.K.Lahiri. Chapter 2. [http://doi.org/10.2174/156720509788486608.].

[86] Plun-Favreau, H.; Lewis, P.A.; Hardy, J.; Martins, L.M.; Wood, N.W., Cancer and neurodegeneration: between the devil and the deep blue sea. PLoS genetics 2010, 6, e1001257. [http://doi.org/10.1371/journal.pgen.1001257].

[87] Seo, J.; Park, M., Molecular crosstalk between cancer and neurodegenerative diseases. Cell. Mol. Life Sci. 2020, 77, 2659-2680. [http://doi.org/10.1007/s00018-019-03428-3.].

[88] Houck, A.L.; Seddighi, S.; Driver, J.A., At the crossroads between neurodegeneration and cancer: a review of overlapping biology and its implications. Current aging science 2018, 11, 77-89. [http://doi.org/10.2174/1874609811666180223154436.].

[89] Kennedy, S.R.; Loeb, L.A.; Herr, A.J., Somatic mutations in aging, cancer and neurodegeneration. Mech. Ageing Dev. 2012, 133, 118-126. [http://doi.org/10.1016/j.mad.2011.10.009].

[90] Migliore, L.; Coppede, F., Genetic and environmental factors in cancer and neurodegenerative diseases. Mutat. Res. 2002, 512, 135-153. [http://doi.org/10.1016/s1383-5742(02)00046-7].

[91] Grunicke, H.; Maly, K.; Oberhuber, H.; Doppler, W.; Hoflacher, J.; Hochleitner, B.W.; Jaggi, R.; Groner, B., Role of Na+/H+Antiporter in Growth Stimulation by Ha-ras. In Plasma Membrane Oxidoreductases in Control of Animal and Plant Growth, Springer: 1988; pp 369-381.

[92] Doppler, W.; Jaggi, R.; Groner, B., Induction of v-mos and activated Ha-ras oncogene expression in quiescent NIH 3T3 cells causes intracellular alkalinisation and cell-cycle progression. Gene 1987, 54, 147-153. [http://doi.org/10.1016/0378-1119(87)90357$\underline{x}$.

[93] Mohammadi, M., Brief note on multiple sclerosis. J Mult Scler (Foster City) 2021, 8, 1-10.

[94] Mulero, P.; Midaglia, L.; Montalban, X., Ocrelizumab: a new milestone in multiple sclerosis therapy. Ther. Adv. Neurol. Disord. 2018, 11, 1756286418773025. [http://doi.org/10.1177/1756286418773025].

[95] Syed, Y.Y., Ocrelizumab: A Review in Multiple Sclerosis. CNS Drugs 2018, 32, 883-890. [http://doi.org/10.1007/s40263-018-05687].

[96] Corthals, A.P., Multiple sclerosis is not a disease of the immune system. The Quarterly review of biology 2011, 86, 287-321. [http://doi.org/10.1086/662453.].

[97] Jagielska, A.; Wilhite, K.D.; Van Vliet, K.J., Extracellular acidic $\mathrm{pH}$ inhibits oligodendrocyte precursor viability, migration, and differentiation. PLoS One 2013, 8, e76048. [http://doi.org/10.1371/journal.pone.0076048].

[98] Makowski, L.; Chaib, M.; Rathmell, J.C., Immunometabolism: From basic mechanisms to translation. Immunol. Rev. 2020, 295, 514. [http://doi.org/10.1111/imr.12858].

[99] Marches, R.; Vitetta, E.S.; Uhr, J.W., A role for intracellular $\mathrm{pH}$ in membrane IgM-mediated cell death of human B lymphomas. Proc. Natl. Acad. Sci. U. S. A. 2001, 98, 3434-3439. [http://doi.org/10.1073/pnas.061028998].

[100] McCarty, M.F.; Whitaker, J., Manipulating tumor acidification as a cancer treatment strategy. Altern. Med. Rev. 2010, 15, 264272.

[101] Lercher, A.; Baazim, H.; Bergthaler, A., Systemic Immunometabolism: Challenges and Opportunities. Immunity 2020, 53, 496509. [http://doi.org/10.1016/j.immuni.2020.08.012].

[102] Wang, A.; Luan, H.H.; Medzhitov, R., An evolutionary perspective on immunometabolism. Science 2019 , 363. [http://doi.org/10.1126/science.aar3932].

[103] Chesler, M., Regulation and modulation of $\mathrm{pH}$ in the brain. Physiol. Rev. 2003, 83, 1183-1221. [http://doi.org/10.1152/physrev.00010.2003].

[104] Takahashi, K.I.; Copenhagen, D.R., Modulation of neuronal function by intracellular pH. Neurosci. Res. 1996, $24,109-116$. [http://doi.org/10.1016/0168-0102(95)00989-2].

[105] Choi, D.W., Calcium: still center-stage in hypoxic-ischemic neuronal death. Trends Neurosci. 1995, 18, 58-60. [http://doi.org/doi.org/10.1016/0166-2236(95)80018-W].

[106] Peers, C.; Scragg, J.L.; Boyle, J.P.; Fearon, I.M.; Taylor, S.C.; Green, K.N.; Webster, N.J.; Ramsden, M.; Pearson, H.A., A central role for ROS in the functional remodelling of L-type Ca2+ channels by hypoxia. Philos. Trans. R. Soc. Lond. B Biol. Sci. 2005, 360, 2247-2254. [http://doi.org/10.1098/rstb.2005.1761].

[107] Ryu, W.-I.; Bormann, M.K.; Shen, M.; Kim, D.; Forester, B.; Park, Y.; So, J.; Seo, H.; Sonntag, K.-C.; Cohen, B.M., Brain cells derived from Alzheimer's disease patients have multiple specific innate abnormalities in energy metabolism. Mol. Psychiatry 2021, 1-13. [http://doi.org/10.1038/s41380-021-01068-3].

[108] Dodge, J.C.; Treleaven, C.M.; Fidler, J.A.; Tamsett, T.J.; Bao, C.; Searles, M.; Taksir, T.V.; Misra, K.; Sidman, R.L.; Cheng, S.H., et al., Metabolic signatures of amyotrophic lateral sclerosis reveal insights into disease pathogenesis. Proc. Natl. Acad. Sci. U. S. A. 2013, 110, 10812-10817. [http://doi.org/10.1073/pnas.1308421110].

[109] Xiong, Z.G.; Zhu, X.M.; Chu, X.P.; Minami, M.; Hey, J.; Wei, W.L.; MacDonald, J.F.; Wemmie, J.A.; Price, M.P.; Welsh, M.J., et al., Neuroprotection in ischemia: blocking calcium-permeable acid-sensing ion channels. Cell 2004, 118, 687-698. [http://doi.org/10.1016/j.cell.2004.08.026]. 
[110] Brisson, L.; Driffort, V.; Benoist, L.; Poet, M.; Counillon, L.; Antelmi, E.; Rubino, R.; Besson, P.; Labbal, F.; Chevalier, S., et al., $\mathrm{NaV} 1.5 \mathrm{Na}(+)$ channels allosterically regulate the NHE-1 exchanger and promote the activity of breast cancer cell invadopodia. J. Cell Sci. 2013, 126, 4835-4842. [http://doi.org/10.1242/jcs.123901].

[111] Harguindey, S.; Arranz, J.L.; Polo Orozco, J.D.; Rauch, C.; Fais, S.; Cardone, R.A.; Reshkin, S.J., Cariporide and other new and powerful NHE1 inhibitors as potentially selective anticancer drugs--an integral molecular/biochemical/metabolic/clinical approach after one hundred years of cancer research. J. Transl. Med. 2013, 11, 282. [http://doi.org/10.1186/1479-5876-11-282].

[112] Durham-Lee, J.C.; Mokkapati, V.U.; Johnson, K.M.; Nesic, O., Amiloride improves locomotor recovery after spinal cord injury. J. Neurotrauma 2011, 28, 1319-1326. [http://doi.org/10.1089/neu.2011.1921].

[113] Roger, S.; Le Guennec, J.Y.; Besson, P., Particular sensitivity to calcium channel blockers of the fast inward voltage-dependent sodium current involved in the invasive properties of a metastastic breast cancer cell line. Br. J. Pharmacol. 2004, 141, 610-615. [http://doi.org/10.1038/sj.bjp.0705649].

[114] Kellenberger, S.; Schild, L., International Union of Basic and Clinical Pharmacology. XCI. structure, function, and pharmacology of acid-sensing ion channels and the epithelial Na+ channel. Pharmacol. Rev. 2015, 67, 1-35. [http://doi.org/10.1124/pr.114.009225].

[115] Yermolaieva, O.; Leonard, A.S.; Schnizler, M.K.; Abboud, F.M.; Welsh, M.J., Extracellular acidosis increases neuronal cell calcium by activating acid-sensing ion channel 1a. Proc. Natl. Acad. Sci. U. S. A. 2004, $101,6752-6757$. [http://doi.org/10.1073/pnas.0308636100].

[116] Petroff, E.; Leonard, A.S.; Schnizler, M.K.; Abboud, F.M.; Welsh, M.J., Extracellular Acidosis Increases Neuronal Cell Calcium By Activating Acid-Sensing Ion Channel 1a. 2004.

[117] Vergo, S.; Craner, M.J.; Etzensperger, R.; Attfield, K.; Friese, M.A.; Newcombe, J.; Esiri, M.; Fugger, L., Acid-sensing ion channel 1 is involved in both axonal injury and demyelination in multiple sclerosis and its animal model. Brain 2011, 134, 571-584. [http://doi.org/10.1093/brain/awq337].

[118] Ding, D.; Moskowitz, S.I.; Li, R.; Lee, S.B.; Esteban, M.; Tomaselli, K.; Chan, J.; Bergold, P.J., Acidosis induces necrosis and apoptosis of cultured hippocampal neurons. Exp. Neurol. 2000, 162, 1-12. [http://doi.org/10.1006/exnr.2000.7226].

[119] Flogel, U.; Willker, W.; Leibfritz, D., Regulation of intracellular pH in neuronal and glial tumour cells, studied by multinuclear NMR spectroscopy. NMR Biomed. 1994, 7, 157-166. [http://doi.org/10.1002/nbm.1940070402].

[120] Yao, H.; Ma, E.; Gu, X.Q.; Haddad, G.G., Intracellular pH regulation of CA1 neurons in $\mathrm{Na}(+) / \mathrm{H}(+)$ isoform 1 mutant mice. J. Clin. Invest. 1999, 104, 637-645. [http://doi.org/10.1172/JCI6785].

[121] Waxman, S.G.; Lo, A.C., Blocking the axonal injury cascade: neuroprotection in multiple sclerosis and its models. Multiple Sclerosis as a Neuronal Disease. London: Elsevier 2005, 435-449. [http://doi.org/10.1016/B978-012738761-1/50030-4].

[122] Cengiz, P.; Kintner, D.B.; Chanana, V.; Yuan, H.; Akture, E.; Kendigelen, P.; Begum, G.; Fidan, E.; Uluc, K.; Ferrazzano, P., et al., Sustained $\mathrm{Na}+\mathrm{H}+$ exchanger activation promotes gliotransmitter release from reactive hippocampal astrocytes following oxygen-glucose deprivation. PLoS One 2014, 9, e84294. [http://doi.org/10.1371/journal.pone.0084294].

[123] Harguindey, S., Use of $\mathrm{Na}+/ \mathrm{H}+$ antiporter inhibitors as a novel approach to cancer treatment. In: Amiloride and its analogs: unique cation transport inhibitors. New York: VCH Publishers Inc 1992, 317-334.

[124] Harguindey, S.; Gonzalez Molinillo, J.; Chinchilla, D.; Reshkin, S.; Tomoda, A. In Further Along a Clinical Protocol Using a Cocktail of PTIs in Human Cancer, ISPDC Abstract Book, 2nd ISPD Meeting, Nice, France, 18-19, 2011; 2011.

[125] Harguindey, S.; Orive, G.; Pedraz, J.L.; Bello, G.; Arranz, J.L.; Samaniego, J.M., Apparent cure of a case of metastatic ovarian carcinoma after the chronic treatment with $\mathrm{Na}+\mathrm{H}+$ antiport inhibitors. Oncologia 2002, 25, 62-66.

[126] Matthews, H.; Ranson, M.; Kelso, M.J., Anti-tumour/metastasis effects of the potassium-sparing diuretic amiloride: an orally active anti-cancer drug waiting for its call-of-duty? Int. J. Cancer 2011, 129, 2051-2061. [http://doi.org/10.1002/ijc.26156].

[127] Rodgers, H.C.; Knox, A.J., The effect of topical benzamil and amiloride on nasal potential difference in cystic fibrosis. Eur. Respir. J. 1999, 14, 693-696. [http://doi.org/10.1034/j.1399-3003.1999.14c32.x].

[128] Rash, L.D., Acid-sensing ion channel pharmacology, past, present, and future.... In Adv. Pharmacol., Elsevier: 2017; Vol. 79, pp 35-66.

[129] Siegel, M.; Shankle, L.; Hwang, S.; Ogdie, A., The 2017 National Psoriasis Foundation Research Symposium. J Psoriasis Psoriatic Arthritis 2018, 3, 15-17. [http://doi.org/10.1177/2475530317753854].

[130] Lee, B.K.; Jung, Y.S., The Na+/H+ exchanger-1 inhibitor cariporide prevents glutamate-induced necrotic neuronal death by inhibiting mitochondrial Ca2+ overload. J. Neurosci. Res. 2012, 90, 860-869. [http://doi.org/10.1002/jnr.22818].

[131] Boiko, N.; Kucher, V.; Eaton, B.A.; Stockand, J.D., Inhibition of neuronal degenerin/epithelial Na+ channels by the multiple sclerosis drug 4-aminopyridine. J. Biol. Chem. 2013, 288, 9418-9427. [http://doi.org/10.1074/jbc.M112.449413].

[132] Kostadinova, I.; Danchev, N., 4-aminopyridine-the new old drug for the treatment of neurodegenerative diseases. Pharmacia 2019, 66, 67. [http://doi.org/10.3897/pharmacia.66.e35976].

[133] Chen, X.; Xu, Z.; Zeng, S.; Wang, X.; Liu, W.; Qian, L.; Wei, J.; Yang, X.; Shen, Q.; Gong, Z., et al., The Molecular Aspect of Antitumor Effects of Protease Inhibitor Nafamostat Mesylate and Its Role in Potential Clinical Applications. Front. Oncol. 2019, 9, 852. [http://doi.org/10.3389/fonc.2019.00852].

[134] Chen, B.; Sun, L.; Zhang, X., Integration of microbiome and epigenome to decipher the pathogenesis of autoimmune diseases. J. Autoimmun. 2017, 83, 31-42. [http://doi.org/10.1016/j.jaut.2017.03.009].

[135] Haghikia, A.; Jorg, S.; Duscha, A.; Berg, J.; Manzel, A.; Waschbisch, A.; Hammer, A.; Lee, D.H.; May, C.; Wilck, N., et al., Dietary Fatty Acids Directly Impact Central Nervous System Autoimmunity via the Small Intestine. Immunity 2015, 43, 817-829. [http://doi.org/10.1016/j.immuni.2015.09.007]. 
[136] Chen, T.; Noto, D.; Hoshino, Y.; Mizuno, M.; Miyake, S., Butyrate suppresses demyelination and enhances remyelination. J. Neuroinflammation 2019, 16, 165. [http://doi.org/10.1186/s12974-019-1552-y].

[137] Arce, V.M.; Devesa, P.; Devesa, J., Role of growth hormone (GH) in the treatment on neural diseases: from neuroprotection to neural repair. Neurosci. Res. 2013, 76, 179-186. [http://doi.org/10.1016/j.neures.2013.03.014].

[138] Devesa, J.; Reimunde, P.; Devesa, P.; Barbera, M.; Arce, V., Growth hormone (GH) and brain trauma. Horm. Behav. 2013, 63, 331344. [http://doi.org/10.1016/j.yhbeh.2012.02.022].

[139] Anitua, E.; Pascual, C.; Perez-Gonzalez, R.; Antequera, D.; Padilla, S.; Orive, G.; Carro, E., Intranasal delivery of plasma and platelet growth factors using PRGF-Endoret system enhances neurogenesis in a mouse model of Alzheimer's disease. PLoS One 2013, 8, e73118. [http://doi.org/10.1371/journal.pone.0073118].

[140] Anitua, E.; Pascual, C.; Perez-Gonzalez, R.; Orive, G.; Carro, E., Intranasal PRGF-Endoret enhances neuronal survival and attenuates NF-kappaB-dependent inflammation process in a mouse model of Parkinson's disease. J. Control. Release 2015, 203, 170-180. [http://doi.org/10.1016/j.jconrel.2015.02.030].

[141] Devesa, J.; Lema, H.; Zas, E.; Munin, B.; Taboada, P.; Devesa, P., Learning and Memory Recoveries in a Young Girl Treated with Growth Hormone and Neurorehabilitation. J Clin Med 2016, 5, 14. [http://doi.org/10.3390/jcm5020014].

[142] Åberg, N.D.; Brywe, K.G.; Isgaard, J., Aspects of growth hormone and insulin-like growth factor-I related to neuroprotection, regeneration, and functional plasticity in the adult brain. TheScientificWorldJournal 2006, 6, 53-80.

[143] Devesa, P.; Gelabert, M.; Gonźlez-Mosquera, T.; Gallego, R.; Luis Relova, J.; Devesa, J.; Arce, V.M., Growth hormone treatment enhances the functional recovery of sciatic nerves after transection and repair. Muscle Nerve 2012, 45, 385-392. [http://doi.org/https://doi.org/10.1002/mus.22303].

[144] Heredia, M.; Fuente, A.; Criado, J.; Yajeya, J.; Devesa, J.; Riolobos, A.S., Early growth hormone (GH) treatment promotes relevant motor functional improvement after severe frontal cortex lesion in adult rats. Behav. Brain Res. 2013, 247, 48-58. [http://doi.org/10.1016/j.bbr.2013.03.012].

[145] Diaz, M.E.; Miquet, J.G.; Rossi, S.P.; Irene, P.E.; Sotelo, A.I.; Frungieri, M.B.; Turyn, D.; Gonzalez, L., GH administration patterns differently regulate epidermal growth factor signaling. J. Endocrinol. 2014, 221, 309-323. [http://doi.org/10.1530/JOE-13-0447].

[146] Sohmiya, M.; Ishikawa, K.; Kato, Y., Stimulation of erythropoietin secretion by continuous subcutaneous infusion of recombinant human GH in anemic patients with chronic renal failure. Eur. J. Endocrinol. 1998, 138, 302-306. [http://doi.org/10.1530/eje.0.1380302].

[147] Scharfmann, R.; Atouf, F.; Tazi, A.; Czernichow, P., Growth hormone and prolactin regulate the expression of nerve growth factor receptors in INS-1 cells. Endocrinology 1994, 134, 2321-2328. [http://doi.org/10.1210/endo.134.6.8194458].

[148] Devesa, J.; Devesa, P.; Reimunde, P.; Arce, V., Growth Hormone and Kynesitherapy for Brain Injury Recovery. Brain Injury Pathogenesis, Monitoring, Recovery and Management. In: Brain Injury-Pathogenesis, Monitoring, Recovery and Management, 1st edition, Chapter:21, Publisher: In Tech. (Ed) A, Agrawal. 2012, 417-454. [http://doi.org/10.5772/26998].

[149] Devesa, J.; Almenglo, C.; Devesa, P., Multiple Effects of Growth Hormone in the Body: Is it Really the Hormone for Growth? Clin Med Insights Endocrinol Diabetes 2016, 9, 47-71. [http://doi.org/10.4137/cmed.s38201].

[150] Chung, J.Y.; Kim, H.J.; Kim, M., The protective effect of growth hormone on Cu/Zn superoxide dismutase-mutant motor neurons. BMC Neurosci. 2015, 16, 1. [http://doi.org/10.1186/s12868-015-0140-z].

[151] Doulah, A.H.; Rohani, A.H.; Khaksari Haddad, M.; Motamedi, F.; Farbood, Y.; Badavi, M.; Malek, M.; Sarkaki, A., The effect of peripheral administration of growth hormone on AD-like cognitive deficiency in NBM-lesioned rats. Neurosci. Lett. 2009, 466, 47-51. [http://doi.org/10.1016/j.neulet.2009.09.016].

[152] Saez, J.M., Possible usefulness of growth hormone/insulin-like growth factor-I axis in Alzheimer's disease treatment. Endocr. Metab. Immune Disord. Drug Targets 2012, 12, 274-286. [http://doi.org/10.2174/187153012802002857].

[153] Sacca, F.; Quarantelli, M.; Rinaldi, C.; Tucci, T.; Piro, R.; Perrotta, G.; Carotenuto, B.; Marsili, A.; Palma, V.; De Michele, G., et al., A randomized controlled clinical trial of growth hormone in amyotrophic lateral sclerosis: clinical, neuroimaging, and hormonal results. J. Neurol. 2012, 259, 132-138. [http://doi.org/10.1007/s00415-011-6146-2].

[154] Devesa, J.; Diaz-Getino, G.; Rey, P.; Garcia-Cancela, J.; Loures, I.; Nogueiras, S.; Hurtado de Mendoza, A.; Salgado, L.; Gonzalez, M.; Pablos, T., et al., Brain Recovery after a Plane Crash: Treatment with Growth Hormone (GH) and Neurorehabilitation: A Case Report. Int. J. Mol. Sci. 2015, 16, 30470-30482. [http://doi.org/10.3390/ijms161226244].

[155] Devesa, J.; Alonso, A.; Lopez, N.; Garcia, J.; Puell, C.I.; Pablos, T.; Devesa, P., Growth Hormone (GH) and Rehabilitation Promoted Distal Innervation in a Child Affected by Caudal Regression Syndrome. Int. J. Mol. Sci. 2017 , 18. [http://doi.org/10.3390/ijms18010230].

[156] Åberg, N.D.; Johansson, U.E.; Åberg, M.A.; Hellström, N.A.; Lind, J.; Bull, C.; Isgaard, J.r.; Anderson, M.F.; Oscarsson, J.; Eriksson, P.S., Peripheral infusion of insulin-like growth factor-I increases the number of newborn oligodendrocytes in the cerebral cortex of adult hypophysectomized rats. Endocrinology 2007, 148, 3765-3772. [http://doi.org/10.1210/en.2006-1556].

[157] Nyberg, F.; Hallberg, M., Growth hormone and cognitive function. Nat. Rev. Endocrinol. 2013, 9, 357-365. [http://doi.org/10.1038/nrendo.2013.78].

[158] Cardinali, D.P.; Pagano, E.S.; Scacchi Bernasconi, P.A.; Reynoso, R.; Scacchi, P., Melatonin and mitochondrial dysfunction in the central nervous system. Horm. Behav. 2013, 63, 322-330. [http://doi.org/10.1016/j.yhbeh.2012.02.020].

[159] Olcese, J.M.; Cao, C.; Mori, T.; Mamcarz, M.B.; Maxwell, A.; Runfeldt, M.J.; Wang, L.; Zhang, C.; Lin, X.; Zhang, G., et al., Protection against cognitive deficits and markers of neurodegeneration by long-term oral administration of melatonin in a transgenic model of Alzheimer disease. J. Pineal Res. 2009, 47, 82-96. [http://doi.org/10.1111/j.1600-079X.2009.00692.x]. 
[160] Rudnitskaya, E.A.; Muraleva, N.A.; Maksimova, K.Y.; Kiseleva, E.; Kolosova, N.G.; Stefanova, N.A., Melatonin Attenuates Memory Impairment, Amyloid-beta Accumulation, and Neurodegeneration in a Rat Model of Sporadic Alzheimer's Disease. J. Alzheimers Dis. 2015, 47, 103-116. [http://doi.org/10.3233/JAD-150161].

[161] Manchester, L.C.; Coto-Montes, A.; Boga, J.A.; Andersen, L.P.; Zhou, Z.; Galano, A.; Vriend, J.; Tan, D.X.; Reiter, R.J., Melatonin: an ancient molecule that makes oxygen metabolically tolerable. J. Pineal Res. 2015, 59, 403-419. [http://doi.org/10.1111/jpi.12267].

[162] Rong, B.; Wu, Q.; Reiter, R.J.; Sun, C., The mechanism of oral melatonin ameliorates intestinal and adipose lipid dysmetabolism through reducing Escherichia Coli-derived lipopolysaccharide. Cellular and Molecular Gastroenterology and Hepatology 2021, 12, 1643-1667. [http://doi.org/10.1016/j.jcmgh.2021.06.024].

[163] López-González, A.; Álvarez-Sánchez, N.; Lardone, P.J.; Cruz-Chamorro, I.; Martínez-López, A.; Guerrero, J.M.; Reiter, R.J.; Carrillo-Vico, A., Melatonin treatment improves primary progressive multiple sclerosis: a case report. J. Pineal Res. 2015, 58, 173-177. [http://doi.org/10.1111/jpi.12203].

[164] Giovannoni, G.; Heales, S.J.; Land, J.M.; Thompson, E.J., The potential role of nitric oxide in multiple sclerosis. Mult. Scler. 1998, 4, 212-216. [http://doi.org/10.1177/135245859800400323].

[165] Smith, K.J.; Lassmann, H., The role of nitric oxide in multiple sclerosis. Lancet Neurol. 2002, 1, $232-241$. [http://doi.org/10.1016/s1474-4422(02)00102-3].

[166] Hausladen, A.; Fridovich, I., Superoxide and peroxynitrite inactivate aconitases, but nitric oxide does not. J. Biol. Chem. 1994, 269, 29405-29408. [http://doi.org/10.1016/0014-5793(94)80087-1].

[167] Brown, G.C., Nitric oxide regulates mitochondrial respiration and cell functions by inhibiting cytochrome oxidase. FEBS Lett. 1995, 369, 136-139. [http://doi.org/10.1016/0014-5793(95)00763-y].

[168] Ding, M.; St Pierre, B.A.; Parkinson, J.F.; Medberry, P.; Wong, J.L.; Rogers, N.E.; Ignarro, L.J.; Merrill, J.E., Inducible nitric-oxide synthase and nitric oxide production in human fetal astrocytes and microglia. A kinetic analysis. J. Biol. Chem. 1997, 272, 1132711335. [http://doi.org/10.1074/jbc.272.17.11327].

[169] Bolanos, J.P.; Peuchen, S.; Heales, S.J.; Land, J.M.; Clark, J.B., Nitric oxide-mediated inhibition of the mitochondrial respiratory chain in cultured astrocytes. J. Neurochem. 1994, 63, 910-916. [http://doi.org/10.1046/j.1471-4159.1994.63030910.x].

[170] Bolaños, J.P.; Heales, S.J., Persistent mitochondrial damage by nitric oxide and its derivatives: neuropathological implications. Front. Neuroenergetics 2010, 2, 1. [http://doi.org/doi.org/10.3389/neuro.14.001.2010].

[171] Inoue, S.; Kawanishi, S., Oxidative DNA damage induced by simultaneous generation of nitric oxide and superoxide. FEBS Lett. 1995, 371, 86-88. [http://doi.org/10.1016/0014-5793(95)00873-8].

[172] Mateo, R.B.; Reichner, J.S.; Mastrofrancesco, B.; Kraft-Stolar, D.; Albina, J.E., Impact of nitric oxide on macrophage glucose metabolism and glyceraldehyde-3-phosphate dehydrogenase activity. Am. J. Physiol. 1995, 268, C669-675. [http://doi.org/10.1152/ajpcell.1995.268.3.C669].

[173] Park, Y.M.; Lee, W.T.; Bokara, K.K.; Seo, S.K.; Park, S.H.; Kim, J.H.; Yenari, M.A.; Park, K.A.; Lee, J.E., The multifaceted effects of agmatine on functional recovery after spinal cord injury through Modulations of BMP-2/4/7 expressions in neurons and glial cells. PLoS One 2013, 8, e53911. [http://doi.org/10.1371/journal.pone.0053911].

[174] Leung, G.; Sun, W.; Zheng, L.; Brookes, S.; Tully, M.; Shi, R., Anti-acrolein treatment improves behavioral outcome and alleviates myelin damage in experimental autoimmune enchephalomyelitis mouse. Neuroscience 2011, 173, 150-155. [http://doi.org/10.1016/j.neuroscience.2010.11.018].

[175] Tully, M.; Shi, R., New insights in the pathogenesis of multiple sclerosis - role of acrolein in neuronal and myelin damage. Int. J. Mol. Sci. 2013, 14, 20037-20047. [http://doi.org/10.3390/ijms141020037].

[176] Wang, J.; Zhao, C.; Kong, P.; Bian, G.; Sun, Z.; Sun, Y.; Guo, L.; Li, B., Methylene blue alleviates experimental autoimmune encephalomyelitis by modulating AMPK/SIRT1 signaling pathway and Th17/Treg immune response. J. Neuroimmunol. 2016, 299, 45-52. [http://doi.org/10.1016/j.jneuroim.2016.08.014].

[177] Ommati, M.M.; Azarpira, N.; Khodaei, F.; Niknahad, H.; Gozashtegan, V.; Heidari, R., Methylene blue treatment enhances mitochondrial function and locomotor activity in a C57BL/6 mouse model of multiple sclerosis. Trends in Pharmaceutical Sciences 2020, 6, 29-42. [http://doi.org/10.30476/TIPS.2020.85962.1044].

[178] Lougheed, R.; Turnbull, J., Lack of effect of methylene blue in the SOD1 G93A mouse model of amyotrophic lateral sclerosis. PLoS One 2011, 6, e23141. [http://doi.org/10.1371/journal.pone.0023141].

[179] Bencze, G.; Bencze, S.; Rivera, K.D.; Watson, J.D.; Hidvegi, M.; Orfi, L.; Tonks, N.K.; Pappin, D.J., Mito-oncology agent: fermented extract suppresses the Warburg effect, restores oxidative mitochondrial activity, and inhibits in vivo tumor growth. Sci. Rep. 2020, 10, 14174. [http://doi.org/10.1038/s41598-020-71118-3].

[180] Mayer, B.; Brunner, F.; Schmidt, K., Inhibition of nitric oxide synthesis by methylene blue. Biochem. Pharmacol. 1993, 45, 367-374. [http://doi.org/10.1016/0006-2952(93)90072-5].

[181] Gentile, A.; De Vito, F.; Fresegna, D.; Rizzo, F.R.; Bullitta, S.; Guadalupi, L.; Vanni, V.; Buttari, F.; Stampanoni Bassi, M.; Leuti, A., et al., Peripheral T cells from multiple sclerosis patients trigger synaptotoxic alterations in central neurons. Neuropathol. Appl. Neurobiol. 2020, 46, 160-170. [http://doi.org/10.1111/nan.12569].

[182] Thomas, A.G.; O'Driscoll, C.M.; Bressler, J.; Kaufmann, W.; Rojas, C.J.; Slusher, B.S., Small molecule glutaminase inhibitors block glutamate release from stimulated microglia. Biochem. Biophys. Res. Commun. 2014, 443, 32-36. [http://doi.org/10.1016/j.bbrc.2013.11.043].

[183] Huang, Y.; Winkler, P.A.; Sun, W.; Lu, W.; Du, J., Architecture of the TRPM2 channel and its activation mechanism by ADPribose and calcium. Nature 2018, 562, 145-149. [http://doi.org/10.1038/s41586-018-0558-4]. 
[184] Tsutsui, M.; Hirase, R.; Miyamura, S.; Nagayasu, K.; Nakagawa, T.; Mori, Y.; Shirakawa, H.; Kaneko, S., TRPM2 Exacerbates Central Nervous System Inflammation in Experimental Autoimmune Encephalomyelitis by Increasing Production of CXCL2 Chemokines. J. Neurosci. 2018, 38, 8484-8495. [http://doi.org/10.1523/JNEUROSCI.2203-17.2018].

[185] Joshi, D.C.; Tewari, B.P.; Singh, M.; Joshi, P.G.; Joshi, N.B., AMPA receptor activation causes preferential mitochondrial Ca2+ load and oxidative stress in motor neurons. Brain Res. 2015, 1616, 1-9. [http://doi.org/10.1016/j.brainres.2015.04.042].

[186] Witte, M.E.; Schumacher, A.-M.; Mahler, C.F.; Bewersdorf, J.P.; Lehmitz, J.; Scheiter, A.; Sánchez, P.; Williams, P.R.; Griesbeck, O.; Naumann, R., Calcium influx through plasma-membrane nanoruptures drives axon degeneration in a model of multiple sclerosis. Neuron 2019, 101, 615-624. e615. [http://doi.org/10.1016/j.neuron.2018.12.023. Epub 2019 Jan 24.].

[187] Hundehege, P.; Epping, L.; Meuth, S.G., Calcium Homeostasis in Multiple Sclerosis. Neurology International Open 2017, 1, E127E135. [http://doi.org/10.1055/s-0043-109031].

[188] Desai, R.A.; Davies, A.L.; Del Rossi, N.; Tachrount, M.; Dyson, A.; Gustavson, B.; Kaynezhad, P.; Mackenzie, L.; van der Putten, M.A.; McElroy, D., et al., Nimodipine Reduces Dysfunction and Demyelination in Models of Multiple Sclerosis. Ann. Neurol. 2020, 88, 123-136. [http://doi.org/10.1002/ana.25749].

[189] Belrose, J.C.; Jackson, M.F., TRPM2: a candidate therapeutic target for treating neurological diseases. Acta Pharmacol. Sin. 2018, 39, 722-732. [http://doi.org/10.1038/aps.2018.31].

[190] Brand-Schieber, E.; Werner, P., Calcium channel blockers ameliorate disease in a mouse model of multiple sclerosis. Exp. Neurol. 2004, 189, 5-9. [http://doi.org/10.1016/j.expneurol.2004.05.023].

[191] Ryter, S.; Choi, A.M., Cell death and repair in lung disease. In Pathobiology of Human Disease: A Dynamic Encyclopedia of Disease Mechanisms, Elsevier Inc.: 2014; pp 2558-2574.

[192] McKenzie, B.A.; Fernandes, J.P.; Doan, M.A.L.; Schmitt, L.M.; Branton, W.G.; Power, C., Activation of the executioner caspases3 and -7 promotes microglial pyroptosis in models of multiple sclerosis. J. Neuroinflammation 2020, $17,253$. [http://doi.org/10.1186/s12974-020-01902-5].

[193] Li, S.; Wu, Y.; Yang, D.; Wu, C.; Ma, C.; Liu, X.; Moynagh, P.N.; Wang, B.; Hu, G.; Yang, S., Gasdermin D in peripheral myeloid cells drives neuroinflammation in experimental autoimmune encephalomyelitis. J. Exp. Med. 2019, $216,2562-2581$. [http://doi.org/10.1084/jem.20190377].

[194] Cid Sánchez, C., Mecanismos de neurodegeneración inducidos por el líquido cefalorraquídeo en la esclerosis múltiple. Universidad Complutense de Madrid, Servicio de Publicaciones: 2005.

[195] Yuan, X.L.; Zhao, Y.P.; Huang, J.; Liu, J.C.; Mao, W.Q.; Yin, J.; Peng, B.W.; Liu, W.H.; Han, S.; He, X.H., A Kv1. 3 channel-specific blocker alleviates neurological impairment through inhibiting T-cell activation in experimental autoimmune encephalomyelitis. CNS Neurosci. Ther. 2018, 24, 967-977. [http://doi.org/10.1111/cns.12848. Epub 2018 Mar 25.].

[196] Wemmie, J.A.; Taugher, R.J.; Kreple, C.J., Acid-sensing ion channels in pain and disease. Nat. Rev. Neurosci. $2013,14,461-471$. [http://doi.org/10.1038/nrn3529].

[197] Carrithers, M.D.; Dib-Hajj, S.; Carrithers, L.M.; Tokmoulina, G.; Pypaert, M.; Jonas, E.A.; Waxman, S.G., Expression of the voltage-gated sodium channel $\mathrm{NaV} 1.5$ in the macrophage late endosome regulates endosomal acidification. J. Immunol. 2007, 178, 7822-7832. [http://doi.org/10.4049/jimmunol.178.12.7822].

[198] Prevarskaya, N.; Ouadid-Ahidouch, H.; Skryma, R.; Shuba, Y., Remodelling of Ca2+ transport in cancer: how it contributes to cancer hallmarks? Philos. Trans. R. Soc. Lond. B Biol. Sci. 2014, 369, 20130097. [http://doi.org/10.1098/rstb.2013.0097].

[199] Hanahan, D.; Weinberg, R.A., The hallmarks of cancer. Cell 2000, 100, 57-70. [http://doi.org/10.1016/s0092-8674(00)81683-9].

[200] Hanahan, D.; Weinberg, R.A., Hallmarks of cancer: the next generation. Cell 2011, 144, 646-674. [http://doi.org/10.1016/j.cell.2011.02.013].

[201] Arcangeli, A.; Becchetti, A., Novel perspectives in cancer therapy: Targeting ion channels. Drug Resist. Updat. 2015, 21-22, 1119. [http://doi.org/10.1016/j.drup.2015.06.002].

[202] De-la-Rosa, V.; Suarez-Delgado, E.; Rangel-Yescas, G.E.; Islas, L.D., Currents through Hv1 channels deplete protons in their vicinity. J. Gen. Physiol. 2016, 147, 127-136. [http://doi.org/10.1085/jgp.201511496].

[203] Wang, Y.; Li, S.J.; Pan, J.; Che, Y.; Yin, J.; Zhao, Q., Specific expression of the human voltage-gated proton channel Hv1 in highly metastatic breast cancer cells, promotes tumor progression and metastasis. Biochem. Biophys. Res. Commun. 2011, 412, 353-359. [http://doi.org/10.1016/j.bbrc.2011.07.102].

[204] Wang, Y.; Li, S.J.; Wu, X.; Che, Y.; Li, Q., Clinicopathological and biological significance of human voltage-gated proton channel Hv1 protein overexpression in breast cancer. J. Biol. Chem. 2012, 287, 13877-13888. [http://doi.org/10.1074/jbc.M112.345280].

[205] Yang, M.; Brackenbury, W.J., Membrane potential and cancer progression. Front. Physiol. 2013,4 , 185. [http://doi.org/10.3389/fphys.2013.00185].

[206] Campos, C.; Rocha, N.B.; Lattari, E.; Paes, F.; Nardi, A.E.; Machado, S., Exercise-induced neuroprotective effects on neurodegenerative diseases: the key role of trophic factors. Expert Rev. Neurother. 2016, 16, 723-734. [http://doi.org/10.1080/14737175.2016.1179582].

[207] L'Allemain, G.; Franchi, A.; Cragoe, E., Jr.; Pouyssegur, J., Blockade of the Na+/H+ antiport abolishes growth factor-induced DNA synthesis in fibroblasts. Structure-activity relationships in the amiloride series. J. Biol. Chem. 1984, 259, 4313-4319. [http://doi.org/10.1016/S0021-9258(17)43047-X].

[208] Wakabayashi, S.; Fafournoux, P.; Sardet, C.; Pouyssegur, J., The Na+/H+ antiporter cytoplasmic domain mediates growth factor signals and controls "H(+)-sensing". Proc. Natl. Acad. Sci. U. S. A. 1992, 89, 2424-2428. [http://doi.org/10.1073/pnas.89.6.2424]. 
[209] Di Sario, A.; Bendia, E.; Svegliati Baroni, G.; Ridolfi, F.; Bolognini, L.; Feliciangeli, G.; Jezequel, A.M.; Orlandi, F.; Benedetti, A., Intracellular pathways mediating $\mathrm{Na}+\mathrm{H}+$ exchange activation by platelet-derived growth factor in rat hepatic stellate cells. Gastroenterology 1999, 116, 1155-1166. [http://doi.org/10.1016/s0016-5085(99)70019-3].

[210] Lin, M.T.; Beal, M.F., Mitochondrial dysfunction and oxidative stress in neurodegenerative diseases. Nature 2006, 443, 787-795. [http://doi.org/10.1038/nature05292].

[211] Monzio Compagnoni, G.; Di Fonzo, A.; Corti, S.; Comi, G.P.; Bresolin, N.; Masliah, E., The role of mitochondria in neurodegenerative diseases: the lesson from Alzheimer's disease and Parkinson's disease. Mol. Neurobiol. 2020, 57, $2959-2980$. [http://doi.org/10.1007/s12035-020-01926-1.].

[212] Johri, A.; Beal, M.F., Mitochondrial dysfunction in neurodegenerative diseases. J. Pharmacol. Exp. Ther. 2012, 342, 619-630. [http://doi.org/10.1124/jpet.112.192138.].

[213] Shi, P.; Wei, Y.; Zhang, J.; Gal, J.; Zhu, H., Mitochondrial dysfunction is a converging point of multiple pathological pathways in amyotrophic lateral sclerosis. J. Alzheimers Dis. 2010, 20, S311-S324. [http://doi.org/10.3233/JAD-2010-100366.].

[214] Manfredi, G.; Xu, Z., Mitochondrial dysfunction and its role in motor neuron degeneration in ALS. Mitochondrion 2005, 5, 7787. [http://doi.org/10.1016/j.mito.2005.01.002].

[215] Colacurcio, D.J.; Nixon, R.A., Disorders of lysosomal acidification-The emerging role of v-ATPase in aging and neurodegenerative disease. Ageing research reviews 2016, 32, 75-88. [http://doi.org/10.1016/j.arr.2016.05.004].

[216] Kallaur, A.P.; Oliveira, S.R.; Simao, A.N.C.; Alfieri, D.F.; Flauzino, T.; Lopes, J.; de Carvalho Jennings Pereira, W.L.; de Meleck Proenca, C.; Borelli, S.D.; Kaimen-Maciel, D.R., et al., Cytokine Profile in Patients with Progressive Multiple Sclerosis and Its Association with Disease Progression and Disability. Mol. Neurobiol. 2017, 54, 2950-2960. [http://doi.org/10.1007/s12035-0169846-x].

[217] Amorini, A.M.; Nociti, V.; Petzold, A.; Gasperini, C.; Quartuccio, E.; Lazzarino, G.; Di Pietro, V.; Belli, A.; Signoretti, S.; Vagnozzi, R., Serum lactate as a novel potential biomarker in multiple sclerosis. Biochimica et Biophysica Acta (BBA)-Molecular Basis of Disease 2014, 1842, 1137-1143. [http://doi.org/10.1016/j.bbadis.2014.04.005].

[218] Lutz, N.W.; Viola, A.; Malikova, I.; Confort-Gouny, S.; Audoin, B.; Ranjeva, J.P.; Pelletier, J.; Cozzone, P.J., Inflammatory multiple-sclerosis plaques generate characteristic metabolic profiles in cerebrospinal fluid. PLoS One 2007, 2, e595. [http://doi.org/10.1371/journal.pone.0000595].

[219] Khatib-Massalha, E.; Bhattacharya, S.; Massalha, H.; Biram, A.; Golan, K.; Kollet, O.; Kumari, A.; Avemaria, F.; PetrovichKopitman, E.; Gur-Cohen, S., Lactate released by inflammatory bone marrow neutrophils induces their mobilization via endothelial GPR81 signaling. Nat. Commun. 2020, 11, 1-18. [http://doi.org/10.1038/s41467-020-17402-2].

[220] Nolt, B.; Tu, F.; Wang, X.; Ha, T.; Winter, R.; Williams, D.L.; Li, C., Lactate and Immunosuppression in Sepsis. Shock 2018, 49, 120-125. [http://doi.org/10.1097/SHK.0000000000000958].

[221] Zwaag, J.; Ter Horst, R.; Blazenovic, I.; Stoessel, D.; Ratter, J.; Worseck, J.M.; Schauer, N.; Stienstra, R.; Netea, M.G.; Jahn, D., et al., Involvement of Lactate and Pyruvate in the Anti-Inflammatory Effects Exerted by Voluntary Activation of the Sympathetic Nervous System. Metabolites 2020, 10, 148. [http://doi.org/10.3390/metabo10040148].

[222] Pucino, V.; Bombardieri, M.; Pitzalis, C.; Mauro, C., Lactate at the crossroads of metabolism, inflammation, and autoimmunity. Eur. J. Immunol. 2017, 47, 14-21. [http://doi.org/10.1002/eji.201646477].

[223] Ratter, J.M.; Rooijackers, H.M.M.; Hooiveld, G.J.; Hijmans, A.G.M.; de Galan, B.E.; Tack, C.J.; Stienstra, R., In vitro and in vivo Effects of Lactate on Metabolism and Cytokine Production of Human Primary PBMCs and Monocytes. Front. Immunol. 2018, 9 , 2564. [http://doi.org/10.3389/fimmu.2018.02564].

[224] Pucino, V.; Certo, M.; Bulusu, V.; Cucchi, D.; Goldmann, K.; Pontarini, E.; Haas, R.; Smith, J.; Headland, S.E.; Blighe, K., Lactate buildup at the site of chronic inflammation promotes disease by inducing CD4+ T cell metabolic rewiring. Cell Metab. 2019, 30, 1055-1074. e1058. [http://doi.org/10.1016/j.cmet.2019.10.004].

[225] Woodcock, E.A.; Hillmer, A.T.; Mason, G.F.; Cosgrove, K.P., Imaging biomarkers of the neuroimmune system among substance use disorders: a systematic review. Molecular neuropsychiatry 2019, 5, 125-146. [http://doi.org/10.1159/000499621.].

[226] Certo, M.; Tsai, C.H.; Pucino, V.; Ho, P.C.; Mauro, C., Lactate modulation of immune responses in inflammatory versus tumour microenvironments. Nat. Rev. Immunol. 2021, 21, 151-161. [http://doi.org/10.1038/s41577-020-0406-2]

[227] Yang, R.; Dunn, J.F., Multiple sclerosis disease progression: contributions from a hypoxia-inflammation cycle. Multiple Sclerosis Journal 2019, 25, 1715-1718. [http://doi.org/10.1177/1352458518791683].

[228] Mason, S., Lactate shuttles in neuroenergetics-homeostasis, allostasis and beyond. Front. Neurosci. 2017, 11, 43. [http://doi.org/10.3389/fnins.2017.00043].

[229] Neunlist, M.; Van Landeghem, L.; Mahé, M.M.; Derkinderen, P.; Des Varannes, S.B.; Rolli-Derkinderen, M., The digestive neuronal-glial-epithelial unit: a new actor in gut health and disease. Nature reviews Gastroenterology $\mathcal{E}$ hepatology 2013, 10, 90100. [http://doi.org/10.1038/nrgastro.2012.221.].

[230] Wang, Y.; Kasper, L.H., The role of microbiome in central nervous system disorders. Brain. Behav. Immun. 2014, $38,1-12$. [http://doi.org/10.1016/j.bbi.2013.12.015].

[231] Maslowski, K.M.; Mackay, C.R., Diet, gut microbiota and immune responses. Nat. Immunol. 2011, 12, 5-9. [http://doi.org/10.1038/ni0111-5].

[232] Ma, H.; Tao, W.; Zhu, S., T lymphocytes in the intestinal mucosa: defense and tolerance. Cell. Mol. Immunol. 2019, 16, $216-224$. [http://doi.org/10.1038/s41423-019-0208-2]. 
[233] Bhaumik, S.; Basu, R., Cellular and Molecular Dynamics of Th17 Differentiation and its Developmental Plasticity in the Intestinal Immune Response. Front. Immunol. 2017, 8, 254. [http://doi.org/10.3389/fimmu.2017.00254].

[234] Khatri, D.K.; Kadbhane, A.; Patel, M.; Nene, S.; Atmakuri, S.; Srivastava, S.; Singh, S.B., Gauging the role and impact of drug interactions and repurposing in neurodegenerative disorders. Curr Res Pharmacol Drug Discov 2021, 2, 100022. [http://doi.org/10.1016/j.crphar.2021.100022].

[235] de la Fuente-Nunez, C.; Meneguetti, B.T.; Franco, O.L.; Lu, T.K., Neuromicrobiology: how microbes influence the brain. ACS Chem. Neurosci. 2018, 9, 141-150. [http://doi.org/doi.org/10.1021/acschemneuro.7b00373].

[236] McQualter, J.L.; Bernard, C.C., Multiple sclerosis: a battle between destruction and repair. J. Neurochem. 2007, 100, 295-306. [http://doi.org/10.1111/j.1471-4159.2006.04232.x.].

[237] Hall, J.A.; Cannons, J.L.; Grainger, J.R.; Dos Santos, L.M.; Hand, T.W.; Naik, S.; Wohlfert, E.A.; Chou, D.B.; Oldenhove, G.; Robinson, M., et al., Essential role for retinoic acid in the promotion of CD4(+) T cell effector responses via retinoic acid receptor alpha. Immunity 2011, 34, 435-447. [http://doi.org/10.1016/j.immuni.2011.03.003].

[238] Pino-Lagos, K.; Guo, Y.; Brown, C.; Alexander, M.P.; Elgueta, R.; Bennett, K.A.; De Vries, V.; Nowak, E.; Blomhoff, R.; Sockanathan, S., A retinoic acid-dependent checkpoint in the development of CD4+ T cell-mediated immunity. J. Exp. Med. 2011, 208, 1767-1775. [http://doi.org/10.1084/jem.20102358].

[239] Grizotte-Lake, M.; Zhong, G.; Duncan, K.; Kirkwood, J.; Iyer, N.; Smolenski, I.; Isoherranen, N.; Vaishnava, S., Commensals Suppress Intestinal Epithelial Cell Retinoic Acid Synthesis to Regulate Interleukin-22 Activity and Prevent Microbial Dysbiosis. Immunity 2018, 49, 1103-1115 e1106. [http://doi.org/10.1016/j.immuni.2018.11.018].

[240] Bernard, F.; Vanhoutte, P.; Bennasroune, A.; Labourdette, G.; Perraut, M.; Aunis, D.; Gaillard, S., pH is an intracellular effector controlling differentiation of oligodendrocyte precursors in culture via activation of the ERK1/2 pathway. J. Neurosci. Res. 2006, 84, 1392-1401. [http://doi.org/10.1002/jnr.21051.].

[241] Mukhin, Y.V.; Garnovskaya, M.N.; Ullian, M.E.; Raymond, J.R., ERK is regulated by sodium-proton exchanger in rat aortic vascular smooth muscle cells. J. Biol. Chem. 2004, 279, 1845-1852. [http://doi.org/https://doi.org/10.1074/jbc.M304907200].

[242] Holscher, H.D., Dietary fiber and prebiotics and the gastrointestinal microbiota. Gut Microbes 2017, 8, 172-184. [http://doi.org/10.1080/19490976.2017.1290756].

[243] Block, M.L.; Zecca, L.; Hong, J.S., Microglia-mediated neurotoxicity: uncovering the molecular mechanisms. Nat. Rev. Neurosci. 2007, 8, 57-69. [http://doi.org/10.1038/nrn2038].

[244] Roberts Jr, E.L.; Sick, T.J., Aging impairs regulation of intracellular pH in rat hippocampal slices. Brain Res. 1996, 735, 339-342. [http://doi.org/10.1016/0006-8993(96)00925-0.].

[245] Harguindey, S.; Polo Orozco, J.; Alfarouk, K.O.; Devesa, J., Hydrogen Ion Dynamics of Cancer and a New Molecular, Biochemical and Metabolic Approach to the Etiopathogenesis and Treatment of Brain Malignancies. Int. J. Mol. Sci. 2019, 20. [http://doi.org/10.3390/ijms20174278].

[246] Dulamea, A.O., Role of Oligodendrocyte Dysfunction in Demyelination, Remyelination and Neurodegeneration in Multiple Sclerosis. Adv. Exp. Med. Biol. 2017, 958, 91-127. [http://doi.org/10.1007/978-3-319-47861-6 7]].

[247] Maghzi, A.H.; Minagar, A.; Waubant, E., Neuroprotection in multiple sclerosis: a therapeutic approach. CNS Drugs 2013, 27, 799-815. [http://doi.org/10.1007/s40263-013-0093-7].

[248] Arun, T.; Tomassini, V.; Sbardella, E.; de Ruiter, M.B.; Matthews, L.; Leite, M.I.; Gelineau-Morel, R.; Cavey, A.; Vergo, S.; Craner, M., et al., Targeting ASIC1 in primary progressive multiple sclerosis: evidence of neuroprotection with amiloride. Brain 2013, 136, 106-115. [http://doi.org/10.1093/brain/aws325].

[249] Pasternak, B.; Svanström, H.; Nielsen, N.M.; Melbye, M.; Hviid, A., Use of amiloride and multiple sclerosis: registry-based cohort studies. Pharmacoepidemiol. Drug Saf. 2012, 21, 890-895. [http://doi.org/10.1002/pds.3269].

[250] Rodgers, H.; Knox, A., The effect of topical benzamil and amiloride on nasal potential difference in cystic fibrosis. Eur. Respir. J. 1999, 14, 693-696. [http://doi.org/10.1034/j.1399-3003.1999.14c32.x.].

[251] Lee, Y.S.; Sayeed, M.M.; Wurster, R.D., Intracellular Ca2+ mediates the cytotoxicity induced by bepridil and benzamil in human brain tumor cells. Cancer Lett. 1995, 88, 87-91. [http://doi.org/10.1016/0304-3835(94)03619-t].

[252] Bezprozvanny, I.; Tsien, R.W., Voltage-dependent blockade of diverse types of voltage-gated Ca2+ channels expressed in Xenopus oocytes by the Ca2+ channel antagonist mibefradil (Ro 40-5967). Mol. Pharmacol. 1995, 48, 540-549.

[253] Devesa, J.; Lima, L.; Tresguerres, J.A., Neuroendocrine control of growth hormone secretion in humans. Trends Endocrinol. Metab. 1992, 3, 175-183. [http://doi.org/10.1016/1043-2760(92)90168-z].

[254] Devesa, P.; Agasse, F.; Xapelli, S.; Almenglo, C.; Devesa, J.; Malva, J.O.; Arce, V.M., Growth hormone pathways signaling for cell proliferation and survival in hippocampal neural precursors from postnatal mice. BMC Neurosci. 2014, 15, 100. [http://doi.org/10.1186/1471-2202-15-100].

[255] Wasinski, F.; Frazão, R.; Donato, J., Effects of growth hormone in the central nervous system. Archives of endocrinology and metabolism 2020, 63, 549-556. [http://doi.org/10.20945/2359-3997000000184.].

[256] Devesa, J.; Nunez, I.; Agra, C.; Bejarano, A.; Devesa, P., Treatment with Growth Hormone (GH) Increased the Metabolic Activity of the Brain in an Elder Patient, Not GH-Deficient, Who Suffered Mild Cognitive Alterations and Had an ApoE 4/3 Genotype. Int. J. Mol. Sci. 2018, 19. [http://doi.org/10.3390/ijms19082294].

[257] Pang, Y.; Zheng, B.; Fan, L.W.; Rhodes, P.G.; Cai, Z., IGF-1 protects oligodendrocyte progenitors against TNF $\alpha$-induced damage by activation of PI3K/Akt and interruption of the mitochondrial apoptotic pathway. Glia 2007, 55, $1099-1107$. [http://doi.org/10.1002/glia.20530.]. 
[258] Gonzalez-Perez, O.; Alvarez-Buylla, A., Oligodendrogenesis in the subventricular zone and the role of epidermal growth factor. Brain Res Rev 2011, 67, 147-156. [http://doi.org/10.1016/j.brainresrev.2011.01.001].

[259] Gironi, M.; Solaro, C.; Meazza, C.; Vaghi, M.; Montagna, L.; Rovaris, M.; Batocchi, A.P.; Nemni, R.; Albertini, R.; Zaffaroni, M., et al., Growth hormone and disease severity in early stage of multiple sclerosis. Mult Scler Int 2013, $2013,836486$. [http://doi.org/10.1155/2013/836486].

[260] Patergnani, S.; Fossati, V.; Bonora, M.; Giorgi, C.; Marchi, S.; Missiroli, S.; Rusielewicz, T.; Wieckowski, M.R.; Pinton, P., Mitochondria in Multiple Sclerosis: Molecular Mechanisms of Pathogenesis. Int. Rev. Cell Mol. Biol. 2017, 328, 49-103. [http://doi.org/10.1016/bs.ircmb.2016.08.003].

[261] Hervias, I.; Beal, M.F.; Manfredi, G., Mitochondrial dysfunction and amyotrophic lateral sclerosis. Muscle Nerve 2006, 33, 598608. [http://doi.org/10.1002/mus.20489].

[262] Weishaupt, J.H.; Bartels, C.; Polking, E.; Dietrich, J.; Rohde, G.; Poeggeler, B.; Mertens, N.; Sperling, S.; Bohn, M.; Huther, G., et al., Reduced oxidative damage in ALS by high-dose enteral melatonin treatment. J. Pineal Res. 2006, 41, 313-323. [http://doi.org/10.1111/j.1600-079X.2006.00377.x].

[263] Farhadi, N.; Oryan, S.; Nabiuni, M., Serum levels of melatonin and cytokines in multiple sclerosis. Biomed J 2014, 37, 90-92. [http://doi.org/10.4103/2319-4170.125885].

[264] Miller, E.; Morel, A.; Saso, L.; Saluk, J., Melatonin redox activity. Its potential clinical applications in neurodegenerative disorders. Curr. Top. Med. Chem. 2015, 15, 163-169. [http://doi.org/0.2174/1568026615666141209160556].

[265] Vakilzadeh, G.; Khodagholi, F.; Ghadiri, T.; Ghaemi, A.; Noorbakhsh, F.; Sharifzadeh, M.; Gorji, A., The Effect of Melatonin on Behavioral, Molecular, and Histopathological Changes in Cuprizone Model of Demyelination. Mol. Neurobiol. 2016, 53, 46754684. [http://doi.org/10.1007/s12035-015-9404-y].

[266] Feng, Z.; Qin, C.; Chang, Y.; Zhang, J.T., Early melatonin supplementation alleviates oxidative stress in a transgenic mouse model of Alzheimer's disease. Free Radic. Biol. Med. 2006, 40, 101-109. [http://doi.org/10.1016/j.freeradbiomed.2005.08.014].

[267] Leone, M.; D'Amico, D.; Moschiano, F.; Fraschini, F.; Bussone, G., Melatonin versus placebo in the prophylaxis of cluster headache: a double-blind pilot study with parallel groups. Cephalalgia 1996, 16, 494-496. [http://doi.org/10.1046/j.14682982.1996.1607494.x].

[268] Pringsheim, T.; Magnoux, E.; Dobson, C.F.; Hamel, E.; Aube, M., Melatonin as adjunctive therapy in the prophylaxis of cluster headache: a pilot study. Headache 2002, 42, 787-792. [http://doi.org/10.1046/j.1526-4610.2002.02181.x].

[269] Hill, S.M.; Frasch, T.; Xiang, S.; Yuan, L.; Duplessis, T.; Mao, L., Molecular mechanisms of melatonin anticancer effects. Integr. Cancer Ther. 2009, 8, 337-346. [http://doi.org/10.1177/1534735409353332].

[270] Srinivasan, V.; Spence, D.W.; Pandi-Perumal, S.R.; Trakht, I.; Cardinali, D.P., Therapeutic actions of melatonin in cancer: possible mechanisms. Integr. Cancer Ther. 2008, 7, 189-203. [http://doi.org/10.1177/1534735408322846].

[271] Reiter, R.J.; Rosales-Corral, S.A.; Tan, D.X.; Acuna-Castroviejo, D.; Qin, L.; Yang, S.F.; Xu, K., Melatonin, a Full Service AntiCancer Agent: Inhibition of Initiation, Progression and Metastasis. Int. J. Mol. Sci. 2017, 18. [http://doi.org/10.3390/ijms18040843].

[272] Menendez-Menendez, J.; Martinez-Campa, C., Melatonin: An Anti-Tumor Agent in Hormone-Dependent Cancers. Int. J. Endocrinol. 2018, 2018, 3271948. [http://doi.org/10.1155/2018/3271948].

[273] Moloudizargari, M.; Moradkhani, F.; Hekmatirad, S.; Fallah, M.; Asghari, M.H.; Reiter, R.J., Therapeutic targets of cancer drugs: Modulation by melatonin. Life Sci. 2021, 267, 118934. [http://doi.org/10.1016/j.lfs.2020.118934].

[274] Guerra, J.; Devesa, J., Usefulness of Melatonin and Other Compounds as Antioxidants and Epidrugs in the Treatment of Head and Neck Cancer. Antioxidants 2022, 11, 35. [http://doi.org/https://doi.org/10.3390/antiox11010035].

[275] Onseng, K.; Johns, N.P.; Khuayjarernpanishk, T.; Subongkot, S.; Priprem, A.; Hurst, C.; Johns, J., Beneficial Effects of Adjuvant Melatonin in Minimizing Oral Mucositis Complications in Head and Neck Cancer Patients Receiving Concurrent Chemoradiation. J. Altern. Complement. Med. 2017, 23, 957-963. [http://doi.org/10.1089/acm.2017.0081].

[276] Elsabagh, H.H.; Moussa, E.; Mahmoud, S.A.; Elsaka, R.O.; Abdelrahman, H., Efficacy of Melatonin in prevention of radiationinduced oral mucositis: A randomized clinical trial. Oral Dis. 2020, 26, 566-572. [http://doi.org/10.1111/odi.13265].

[277] Lozano, A.; Marruecos, J.; Rubio, J.; Farre, N.; Gomez-Millan, J.; Morera, R.; Planas, I.; Lanzuela, M.; Vazquez-Masedo, M.G.; Cascallar, L., et al., Randomized placebo-controlled phase II trial of high-dose melatonin mucoadhesive oral gel for the prevention and treatment of oral mucositis in patients with head and neck cancer undergoing radiation therapy concurrent with systemic treatment. Clin. Transl. Oncol. 2021, 23, 1801-1810. [http://doi.org/10.1007/s12094-021-02586-w].

[278] Canani, R.B.; Costanzo, M.D.; Leone, L.; Pedata, M.; Meli, R.; Calignano, A., Potential beneficial effects of butyrate in intestinal and extraintestinal diseases. World J. Gastroenterol. 2011, 17, 1519-1528. [http://doi.org/10.3748/wjg.v17.i12. 1519

10.3748/wjg.v17.i12.1519].

[279] Rossi, M.; Petralla, S.; Protti, M.; Baiula, M.; Kobrlova, T.; Soukup, O.; Spampinato, S.M.; Mercolini, L.; Monti, B.; Bolognesi, M.L., $\alpha$-Linolenic Acid-Valproic Acid Conjugates: Toward Single-Molecule Polypharmacology for Multiple Sclerosis. ACS Med. Chem. Lett. 2020, 11, 2406-2413. [http://doi.org/doi.org/10.1021/acsmedchemlett.0c00375].

[280] Ochoa-Reparaz, J.; Mielcarz, D.W.; Ditrio, L.E.; Burroughs, A.R.; Foureau, D.M.; Haque-Begum, S.; Kasper, L.H., Role of gut commensal microflora in the development of experimental autoimmune encephalomyelitis. J. Immunol. 2009, 183, 6041-6050. [http://doi.org/10.4049/jimmunol.0900747].

[281] Sell, L.B.; Ramelow, C.C.; Kohl, H.M.; Hoffman, K.; Bains, J.K.; Doyle, W.J.; Strawn, K.D.; Hevrin, T.; Kirby, T.O.; Gibson, K.M., et al., Farnesol induces protection against murine CNS inflammatory demyelination and modifies gut microbiome. Clin. Immunol. 2021, 108766. [http://doi.org/10.1016/j.clim.2021.108766]. 
[282] Ser, H.-L.; Letchumanan, V.; Goh, B.-H.; Wong, S.H.; Lee, L.-H., The Use of Fecal Microbiome Transplant in Treating Human Diseases: Too Early for Poop? Front. Microbiol. 2021, 12, 1005. [http://doi.org/10.3389/fmicb.2021.519836].

[283] Wegener, G.; Volke, V., Nitric oxide synthase inhibitors as antidepressants. Pharmaceuticals 2010, 3, $273-299$. [http://doi.org/10.3390/ph3010273].

[284] Spain, R.; Powers, K.; Murchison, C.; Heriza, E.; Winges, K.; Yadav, V.; Cameron, M.; Kim, E.; Horak, F.; Simon, J., et al., Lipoic acid in secondary progressive MS: A randomized controlled pilot trial. Neurol Neuroimmunol Neuroinflamm 2017, 4 , e374. [http://doi.org/10.1212/NXI.0000000000000374].

[285] Yang, L.; Youngblood, H.; Wu, C.; Zhang, Q., Mitochondria as a target for neuroprotection: role of methylene blue and photobiomodulation. Translational neurodegeneration 2020, 9, 1-22. [http://doi.org/10.1186/s40035-020-00197-z].

[286] Gomes, M.B.; Negrato, C.A., Alpha-lipoic acid as a pleiotropic compound with potential therapeutic use in diabetes and other chronic diseases. Diabetol. Metab. Syndr. 2014, 6, 1-18. [http://doi.org/10.1186/1758-5996-6-80].

[287] Mijnhout, G.S.; Kollen, B.J.; Alkhalaf, A.; Kleefstra, N.; Bilo, H.J., Alpha lipoic Acid for symptomatic peripheral neuropathy in patients with diabetes: a meta-analysis of randomized controlled trials. Int. J. Endocrinol. 2012, 2012, 456279. [http://doi.org/10.1155/2012/456279].

[288] Alfarouk, K.O.; Alhoufie, S.T.S.; Hifny, A.; Schwartz, L.; Alqahtani, A.S.; Ahmed, S.B.M.; Alqahtani, A.M.; Alqahtani, S.S.; Muddathir, A.K.; Ali, H., et al., Of mitochondrion and COVID-19. J. Enzyme Inhib. Med. Chem. 2021, 36, $1258-1267$. [http://doi.org/10.1080/14756366.2021.1937144].

[289] Weitzen, R.; Epstein, N.; Oberman, B.; Shevetz, R.; Hidvegi, M.; Berger, R., Fermented Wheat Germ Extract (FWGE) as a Treatment Additive for Castration-Resistant Prostate Cancer: A Pilot Clinical Trial. Nutr. Cancer 2021, 1-9. [http://doi.org/10.1080/01635581.2021.1952457].

[290] Boros, L.G.; Nichelatti, M.; Shoenfeld, Y., Fermented wheat germ extract (Avemar) in the treatment of cancer and autoimmune diseases. Ann. N. Y. Acad. Sci. 2005, 1051, 529-542. [http://doi.org/10.1196/annals.1361.097].

[291] Jelinek, G.A.; Marck, C.H.; Weiland, T.J.; Pereira, N.; van der Meer, D.M.; Hadgkiss, E.J., Latitude, sun exposure and vitamin D supplementation: associations with quality of life and disease outcomes in a large international cohort of people with multiple sclerosis. BMC Neurol. 2015, 15, 132. [http://doi.org/10.1186/s12883-015-0394-1].

[292] Sintzel, M.B.; Rametta, M.; Reder, A.T., Vitamin D and Multiple Sclerosis: A Comprehensive Review. Neurol Ther 2018, 7, 59-85. [http://doi.org/10.1007/s40120-017-0086-4].

[293] Nicholson, D.W.; Ali, A.; Thornberry, N.A.; Vaillancourt, J.P.; Ding, C.K.; Gallant, M.; Gareau, Y.; Griffin, P.R.; Labelle, M.; Lazebnik, Y.A., et al., Identification and inhibition of the ICE/CED-3 protease necessary for mammalian apoptosis. Nature 1995, 376, 37-43. [http://doi.org/10.1038/376037a0].

[294] Tewari, M.; Quan, L.T.; O'Rourke, K.; Desnoyers, S.; Zeng, Z.; Beidler, D.R.; Poirier, G.G.; Salvesen, G.S.; Dixit, V.M., Yama/CPP32 $\beta$, a mammalian homolog of CED-3, is a CrmA-inhibitable protease that cleaves the death substrate poly (ADPribose) polymerase. Cell 1995, 81, 801-809. [http://doi.org/10.1016/0092-8674(95)90541-3.].

[295] Alnemri, E.S.; Livingston, D.J.; Nicholson, D.W.; Salvesen, G.; Thornberry, N.A.; Wong, W.W.; Yuan, J., Human ICE/CED-3 protease nomenclature. Cell 1996, 87, 171. [http://doi.org/10.1016/s0092-8674(00)81334-3].

[296] Cid, C.; Alvarez-Cermeno, J.C.; Regidor, I.; Plaza, J.; Salinas, M.; Alcazar, A., Caspase inhibitors protect against neuronal apoptosis induced by cerebrospinal fluid from multiple sclerosis patients. J. Neuroimmunol. 2003, 136, 119-124. [http://doi.org/10.1016/s0165-5728(02)00467-8].

[297] Tully, M.; Tang, J.; Zheng, L.; Acosta, G.; Tian, R.; Hayward, L.; Race, N.; Mattson, D.; Shi, R., Systemic Acrolein Elevations in Mice With Experimental Autoimmune Encephalomyelitis and Patients With Multiple Sclerosis. Front. Neurol. 2018, 9, 420. [http://doi.org/10.3389/fneur.2018.00420].

[298] Davis, F.A.; Becker, F.O.; Michael, J.A.; Sorensen, E., Effect of intravenous sodium bicarbonate, disodium edetate (Na2EDTA), and hyperventilation on visual and oculomotor signs in multiple sclerosis. J. Neurol. Neurosurg. Psychiatry 1970, 33, 723-732. [http://doi.org/10.1136/jnnp.33.6.723].

[299] Hoang, B.X.; Le, B.T.; Tran, H.D.; Hoang, C.; Tran, H.Q.; Tran, D.M.; Pham, C.Q.; Pham, T.D.; Ha, T.V.; Bui, N.T., Dimethyl sulfoxide-sodium bicarbonate infusion for palliative care and pain relief in patients with metastatic prostate cancer. J. Pain Palliat. Care Pharmacother. 2011, 25, 350-355. [http://doi.org/10.3109/15360288.2011.606294].

[300] Hoang, B.X.; Tran, D.M.; Tran, H.Q.; Nguyen, P.T.; Pham, T.D.; Dang, H.V.; Ha, T.V.; Tran, H.D.; Hoang, C.; Luong, K.N., et al., Dimethyl sulfoxide and sodium bicarbonate in the treatment of refractory cancer pain. J. Pain Palliat. Care Pharmacother. 2011, 25, 19-24. [http://doi.org/10.3109/15360288.2010.536306].

[301] Hoang, B.X.; Tran, H.Q.; Vu, U.V.; Pham, Q.T.; Shaw, D.G., Palliative treatment for advanced biliary adenocarcinomas with combination dimethyl sulfoxide-sodium bicarbonate infusion and S-adenosyl-l-methionine. J. Pain Palliat. Care Pharmacother. 2014, 28, 206-211. [http://doi.org/10.3109/15360288.2014.938882].

[302] Hoang, B.X.; Shaw, D.G.; Han, B.; Fang, J.Y.; Nimni, M., Acidosis and formaldehyde secretion as a possible pathway of cancer pain and options for improved cancer pain control. J. Pain Palliat. Care Pharmacother. 2015, 29, $276-280$.

[303] Hoang, C.; Nguyen, A.K.; Nguyen, T.Q.; Fang, W.; Han, B.; Hoang, B.X.; Tran, H.D., Application of Dimethyl Sulfoxide as a Therapeutic Agent and Drug Vehicle for Eye Diseases. J. Ocul. Pharmacol. Ther. 2021, 37, 441-451. [http://doi.org/doi.org/10.1089/jop.2021.0043]. 